\title{
Short-Term Plasticity at Primary Afferent Synapse in Rat Spinal Dorsal Horn and Its Biological Function
}

\author{
Ye-hong Wan ${ }^{a}$ Zhong Jian ${ }^{b}$ Wen-ting Wang ${ }^{c}$ Hui Xu $u^{c}$ San-jue $\mathrm{Hu}^{c}$ \\ Gong Ju ${ }^{a}$ \\ ${ }^{a}$ Institute of Neuroscience, Shanghai Jiaotong University, Shanghai; ${ }^{b}$ Institute of Biomedical Engineering, \\ School of Life Science and Technology, Xi'an Jiaotong University, Xi'an, and 'Institute of Neuroscience, \\ The Fourth Military Medical University, Xi'an, PR China
}

\section{Key Words}

Short-term plasticity · Primary afferent synapse $\cdot$ Spinal dorsal horn $\cdot A \delta$-fiber $\cdot$ Excitatory postsynaptic current

\begin{abstract}
Short-term plasticity (STP) is an important element of information processing in neuronal networks. As the first synaptic relay between primary afferent fibers (PAFs) and central neurons, primary afferent synapses in spinal dorsal horn $(\mathrm{DH})$ are essential to the initial processing of somatosensory information. In this research, we examined the STP between A $\delta$-PAFs and spinal DH neurons by patch-clamp recording. Our results showed that depression dominated the STP at primary afferent synapses. The curves of STP had no significant changes in the presence of bicuculline, CTZ or AP-5. Lowering extracellular $\mathrm{Ca}^{2+}$ concentration $\left(\left[\mathrm{Ca}^{2+}\right]_{0}\right.$ ) from 2.4 to $0.8 \mathrm{~mm}$ reduced the depression of synaptic responses at all stimulus rates, while raising $\left[\mathrm{Ca}^{2+}\right]_{0}$ from 2.4 to $4.0 \mathrm{~mm}$ increased the synaptic depression. Increasing the bath temperature from 24 to $32^{\circ} \mathrm{C}$ clearly reduced the depression of all responses. These results indicate that the observed STP is of presynaptic origin and depends on transmitter release. By fitting the experimental data recorded under different conditions, a model of STP was used to quantitatively characterize the observed STP and to analyze the possible mecha-
\end{abstract}

nisms underlying the effects of $\left[\mathrm{Ca}^{2+}\right]_{\mathrm{O}}$ and temperature. Furthermore, using a model neuron receiving synaptic inputs, we found that with this form of STP, postsynaptic DH neurons could detect rate changes in both rapidly-and slowly-firing afferents with equal sensitivity. The present study links the intrinsic STP properties of primary afferent synapses with their role in processing neural information, and provides a basis for further research on the STP in spinal DH and its biological function under in vivo conditions.

Copyright $\odot 2006$ S. Karger AG, Basel

\section{Introduction}

Synaptic transmission between neurons is a dynamic process that exhibits distinctive types of plasticity [1]. During repetitive presynaptic activity, postsynaptic responses will not follow with uniform strength, but be modified in an activity-dependent manner, leading to enhancement, depression or a mixture of both. Shortterm synaptic plasticity, referred to as changes in synaptic efficacy that occur over milliseconds to minutes, has been a subject of intense study for decades [2-6]. Much attention was focused on understanding the mechanism that underlies this type of plasticity and its functional consequences. Research shows that at some synapses, re-

\section{KARGER}

Fax +4161306 1234 E-Mail karger@karger.ch www.karger.com
(C) 2006 S. Karger AG, Basel

$1424-862 X / 06 / 0152-0074 \$ 23.50 / 0$

Accessible online at:

www.karger.com/nsg
Dr. Ye-hong Wan

Institute of Neuroscience, College of Life Science and Biotechnology

Shanghai Jiaotong University, 800 Dongchuan Road

Shanghai 200240 (PR China)

Tel. +86 213420 4287, Fax +86 213420 4270, E-Mail wanyehong@sjtu.edu.cn 
petitive activation can cause enhancement by increasing $\mathrm{Ca}^{2+}$ concentration in the presynaptic terminals. At other synapses, a reduction in neurotransmitter release results in depression, mostly owing to the depletion of readily releasable pool of vesicles. Enhancement and depression can coexist at synapses, and the balance between them depends strongly on the initial probability of release $\left(P_{r}\right)$ : high $P_{r}$ favors depression, while low $P_{r}$ favors enhancement. Short-term plasticity (STP) is now recognized as an important element of information processing in neuronal networks $[1,7,8]$. It plays an essential role in filtering the sensory information [9-11], regulating the gain control [12], balancing the excitation and inhibition [13], removing the redundant correlations in spike trains [14], detecting the synchronous changes in presynaptic activity [15], switching the control of network frequency in rhythmic motor circuits [8], and localizing the source of sound [16].

Spinal dorsal horn (DH) is the major region where primary afferent fibers (PAFs) arising from the periphery terminate and form the first synaptic relay with central neurons. This region is responsible for the initial processing of primary afferent somatosensory information from skin, muscle and viscera. Most small afferents with either fine thinly-myelinated (A $\delta$ ) or unmyelinated (C) fibers transmit nociceptive information, while most large myelinated (A $\beta$ ) afferents function as low-threshold mechanoreceptors [17]. Using spinal cord slices with attached dorsal root, the physiology and pharmacology of synaptic transmission between PAFs and DH neurons have been well studied [18-21]. It is now known that the terminals of PAFs make exclusively excitatory synaptic contacts with DH neurons, most of which are monosynaptic contacts $[18,19,22]$. PAFs use glutamate as the major transmitter; both AMPA and NMDA receptors are involved in the glutamergic synaptic transmission between PAFs and DH neurons, with AMPA receptors playing a predominant role $[19,20]$. Furthermore, early studies have demonstrated that long-term changes in synaptic efficacy, i.e. long-term synaptic plasticity, can be induced at primary afferent synapses by either high- or low-rate stimulation of dorsal root [23-25]. Postsynaptic NMDA receptors proved necessary for the induction of long-term synaptic changes in spinal DH [25].

Up to now, research on the synaptic plasticity in spinal $\mathrm{DH}$ focused mainly on long-term changes. Despite its importance in supporting a variety of synaptic computations, STP has just been preliminarily studied at primary afferent synapses in superficial spinal DH [26]. In this research, by recording monosynaptic excitatory postsyn- aptic currents (EPSCs) from DH neurons, we examined the STP and its possible origin at A $\delta$ primary afferent synapses in rat deep spinal DH (lamina III-V). Experimental data recorded under different conditions were fit with a model of STP to quantitatively describe the temporal transfer characteristics of primary afferent synapses, and to suggest the possible mechanism underlying the effects of extracellular $\mathrm{Ca}^{2+}$ concentration $\left(\left[\mathrm{Ca}^{2+}\right]_{\mathrm{o}}\right)$ and temperature on the STP. With the help of the STP model, the biological function of the STP at primary afferent synapses was explored with a neuronal model that receives synaptic inputs.

\section{Methods}

Subjects

Experiments were performed on transverse spinal cord slices with attached dorsal root that were obtained from Sprague-Dawley rats (18-21 days old). Animal care and use procedures were in accord with the 'Principles of Medical Laboratory Animal Care' issued by the National Ministry of Health.

Tissue Slice Preparation

The method used to obtain spinal cord slices has been described in detail elsewhere $[23,24,27]$. In brief, animals were anesthetized with pentobarbital sodium $(30-40 \mathrm{mg} / \mathrm{kg})$. The lumbrosacral spinal cord (L3-S1) with long $(8-12 \mathrm{~mm})$ dorsal roots attached was removed and put into the pre-equilibrated artificial cerebrospinal fluid (ACSF) at $1-4^{\circ} \mathrm{C}$. Except the L4 and L5 dorsal roots on one side, all the ventral and dorsal roots were cut off near the root entry zone. A vibratome (753 Vibroslice, Campden, UK) was used to yield several transverse slices $(300 \mu \mathrm{m}$ in thickness) with an attached dorsal root. The obtained slices were placed in ACSF at room temperature (about $24^{\circ} \mathrm{C}$ ). After incubation for at least $1 \mathrm{~h}$, a slice was transferred into a recording chamber, where it was perfused at a rate of about $2-3 \mathrm{ml} / \mathrm{min}$ with ACSF equilibrated with $95 \% \mathrm{O}_{2}$ and $5 \% \mathrm{CO}_{2}$ at about $24^{\circ} \mathrm{C}$. ACSF used in our experiments contained (in $\mathrm{mM}$ ) $\mathrm{NaCl} 124, \mathrm{KCl} 1.9, \mathrm{KH}_{2} \mathrm{PO}_{4}$ 1.2, $\mathrm{MgSO}_{4}$ 1.3, $\mathrm{CaCl}_{2} 2.4, \mathrm{NaHCO}_{3} 26$, and glucose 10 .

Patch-Clamp Recording and Dorsal Root Stimulation

Visually guided patch-clamp recordings were made from neurons in deep DH (lamina III-V), as reported previously [21, 27, 28]. Lamina regions were identified under a $5 \times$ objective, and individual neurons were visualized with a $40 \times$ water-immersion objective under a microscope (BX51WI, Olympus, Japan) equipped with infrared differential interference contrast optics. Recording pipettes had a resistance of about 6-8 $\mathrm{M} \Omega$ when filled with pipette solution containing (in $\mathrm{mM}$ ) potassium gluconate $135, \mathrm{KCl} 5, \mathrm{CaCl}_{2}$ 0.5, $\mathrm{MgCl}_{2}$ 2, EGTA 5, HEPES 5, and Mg-ATP 5 ( $\mathrm{pH}$ 7.3). Whole-cell voltage-clamp recordings were made using an amplifier (Multiclamp 700A, Axon Instruments, USA), with the holding potential $-70 \mathrm{mV}$. Signals were low-pass filtered at $5 \mathrm{kHz}$ and sampled at $10 \mathrm{kHz}$ with an analog-to-digital converter (Digidata 1322A, Axon Instruments), and data were stored on a computer for subsequent off-line analysis. 
Dorsal roots were orthodromically stimulated through a suction electrode with an electronic isolated current stimulator (SEN7203, Nihon Kohden, Japan). To avoid direct activation of DH neurons or central fibers in the spinal cord, current stimuli had a short duration (100-150 $\mu \mathrm{s})$ and low intensities (1.2-1.5 times the threshold required to evoke EPSCs on DH neurons). Dorsal root stimulation under the given experimental conditions was assessed quantitatively. A $\delta$ - and C-fiber-evoked EPSCs were distinguished with two measurements: the conduction velocity of afferent fibers and stimulus threshold $[23,24,29,30]$. The conduction velocity was calculated from the length of dorsal root and the latency between EPSC and the preceding stimulus artifact, with central delay considered to be $1 \mathrm{~ms}$. Under our experimental conditions, A $\delta$-fibers had faster conduction velocities $(2-7 \mathrm{~m} / \mathrm{s})$ and lower threshold (0.3-0.5 mA), while C-fibers had slower velocities $(<1 \mathrm{~m} / \mathrm{s})$ and higher threshold (0.7-1.0 mA). The present study was based mainly on A $\delta$-fiber-evoked monosynaptic responses. Synaptic responses evoked by stimulating A $\delta$-fibers were considered as monosynaptic ones, if their poststimulus latency remained constant and no failures were observed during high-rate $(10$ or $20 \mathrm{~Hz})$ repetitive stimulation $[23,24,29,30]$. Regular stimulus trains containing 10 pulses of different rates and random stimulus trains with Poissondistributed pulses were delivered to dorsal roots. Stimulus trains were separated by 2-min intervals, which were long enough for the first EPSC in each train to keep nearly constant, indicating the full recovery of evoked synaptic release [31, 32].

\section{Data Analysis}

Synaptic efficacy was determined from EPSCs using their peak amplitudes. Peak EPSC amplitude was quantified as the mean amplitude of a 1.0-ms segment centered on the peak location, which was detected using a software (Clampfit 8.0, Axon Instruments) within a user-specified window. Without further illustration, all numerical data were expressed as the mean $\pm \mathrm{SE}$ in the following parts.

To quantitatively characterize the STP at primary afferent synapses, experimental data were fit with a STP model that is based on presynaptic mechanisms described in more accessible synaptic systems. The model was developed by Li and Burke [32] and has successfully fit the excitatory postsynaptic potential (EPSP) data from mouse lumbosacral motoneurons in spinal ventral horn $[32,33]$. This model includes elements similar to those in other formulations [34-37]. The full model includes two independent presynaptic compartments, $N$ and $S$, which are both required for transmitter release. In the baseline state, $N_{1}=N /$ $N_{\max }=1$ and $S_{1}=S / S_{\max }=1$. The product $N_{i} \cdot S_{i}$ represents the fractional population that is able to release transmitter at the $i$-th activation. A constant proportion, $f$, of readily releasable $N_{i} \cdot S_{i}$ elements actually release transmitter at the $i$-th activation and give an EPSC, $R_{i}$. Thus the first response, $R_{1}$, in a train is simply

$$
R_{1}=N_{1} \cdot S_{1} \cdot f
$$

Immediately after activation, the $N_{i}$ and $S_{i}$ fractional populations that actually release transmitter are temporarily inactivated, leaving $N_{i}^{*}$ and $S_{i}^{*}$ fractional populations still able to release transmitter

$$
N_{i}^{*}=N_{i}-R_{i}
$$

and

$$
S_{i}^{*}=S_{i}-R_{i}
$$

The $N_{i}^{*}$ and $S_{i}^{*}$ populations are restored toward $N_{\max }$ and $S_{\max }$ during the intervals between pulses, $\Delta t$, by independent, saturating, exponential processes

$N_{i+1}=N_{i}^{*}+\left(1-N_{i}^{*}\right) \cdot\left[1-\exp \left(-\Delta t / \tau_{N, 0}\right)\right]$

and

$S_{i+1}=S_{i}^{*}+\left(1-S_{i}^{*}\right) \cdot\left[1-\exp \left(-\Delta t / \tau_{S}\right)\right]$

In one-compartment models, $S_{i}$ was set to be 1 at all times. The effect of facilitation during synaptic transmission is simulated by a saturating process in which each activation adds an increment $\Delta P$ that changes transmitter release from competent $N_{i} \cdot S_{i}$ elements, so that the $i$-th EPSC amplitude equation 1 becomes

$R_{i}=N_{i} \cdot S_{i} \cdot f \cdot\left(1+P_{i}\right)$

where $P_{1}=0$ and $P_{i}$ decays exponentially from its value at the $i$-th activation as

$$
P_{i+1}=\left(P_{i}+\Delta P\right) \cdot \exp \left(-\Delta t / \tau_{P}\right)
$$

The effect of $P$ process is removed from some models by setting $\Delta P$ to be 0 . Many studies have shown that repetitive presynaptic activation can speed the restoration of readily releasable transmitter $[4,35,36,38,39]$. This effect is simulated by a saturating process, $M$, with increment $\Delta M$ and exponential decay time constant $\tau_{M}$,

$$
M_{i+1}=\left(M_{i}+\Delta M\right) \cdot \exp \left(-\Delta t / \tau_{M}\right)
$$

Through $M$ process, synaptic activation can change the initial time constant $\tau_{N, 0}$ in equation 4 as

$$
\tau_{N, i+1}=\tau_{N, 0} /\left(1+M_{i+1}\right)
$$

With positive values of $\Delta M, \tau_{N, i+1}$ decreases during repetitive activation, thus increasing the renewal rate of $N_{\mathrm{i}}$. And equation 4 becomes

$$
N_{i+1}=N_{i}^{*}+\left(1-N_{i}^{*}\right) \cdot\left[1-\exp \left(-\Delta t / \tau_{N, i+1}\right)\right]
$$

The effect of $M$ process is removed from some models by setting $\Delta M$ to be 0 . The amplitudes of model EPSC responses in a given train were normalized by the amplitude of the first EPSC, $R_{1}$, in the train. The properties of the model, such as its sensitivity to changes in each of the seven parameters, have been tested and reported in the early studies $[32,33]$.

The summed difference between all experimental $\left(A_{\exp , i}\right)$ and model $\left(A_{\bmod , i}\right)$ responses were measured by calculating the root mean square (RMS) error,

$$
\text { RMS error }=\sqrt{\frac{\sum_{i=1}^{n}\left(A_{\text {exp }, i}-A_{\text {mod }, i}\right)^{2}}{n}}
$$

To extract the parameter sets that produce the best fits, a computer program that embodies equations $1-10$ was written. The program used an iterative search algorithm to find the parameter sets that minimize the RMS errors between experimental and model responses. In each fitting, the program was run until the RMS error was less than $0.1 \%$ or there had been $10^{5}$ iterations. The obtained parameter sets were recorded and compared. 
Computational Simulation of the Biological Function of STP

To explore the functional roles of the STP at primary afferent synapses, we constructed an integrate-and-fire model neuron that receives synaptic inputs [40]. The model neuron obeys the following equation

$$
\tau_{\mathrm{m}} \frac{d V}{d t}=E_{\mathrm{L}}-V-r_{\mathrm{m}} \bar{g}_{\mathrm{S}} P_{\mathrm{S}}\left(V-E_{\mathrm{S}}\right)
$$

where $\tau_{\mathrm{m}}$ represents the membrane time constant of the neuron, $E_{\mathrm{L}}$ represents the resting potential of the neuron, $V$ represents the membrane potential, and $r_{\mathrm{m}} \bar{g}_{\mathrm{S}} P_{\mathrm{S}}\left(V-E_{\mathrm{S}}\right)$ represents synaptic input. In $r_{\mathrm{m}} \bar{g}_{\mathrm{S}} P_{\mathrm{S}}\left(V-E_{\mathrm{S}}\right), r_{\mathrm{m}}$ stands for the specific membrane resistance, $\bar{g}_{S}$ stands for the maximal synaptic conductance when a synapse is activated, $E_{\mathrm{S}}$ stands for the reversal potential of synaptic conductance, and $P_{\mathrm{S}}$ stands for the probability that a postsynaptic channel opens given that the transmitter was released by the presynaptic terminal. To describe the dynamic change of synaptic conductance, $P_{\mathrm{S}}$ has the expression of

$$
P_{\mathrm{S}}=\frac{t}{\tau_{\mathrm{S}}} \exp \left(1-t / \tau_{\mathrm{S}}\right)
$$

where $\tau_{\mathrm{S}}$ represents the synaptic time constant. This expression, called an $\alpha$ function, starts at zero, reaches its peak value at $t=\tau_{\mathrm{S}}$, and then decays with the time constant $\tau_{\mathrm{S}}$. In our research, $\tau_{\mathrm{m}}=$ $50 \mathrm{~ms}, E_{\mathrm{L}}=-70 \mathrm{mV}, E_{\mathrm{S}}=0 \mathrm{mV}$, and $\tau_{\mathrm{S}}=3 \mathrm{~ms}$.

When the membrane potential, i.e. $V$, reached $-55 \mathrm{mV}$, the model neuron fired a spike and $V$ was reset to $-58 \mathrm{mV}$. One thousand synaptic inputs were received by the model neuron we used; the synapses had the $r_{\mathrm{m}} \bar{g}_{\mathrm{S}}$ of 0.02 when STP was not included, and the $r_{\mathrm{m}} \bar{g}_{\mathrm{S}}$ of 0.071 when STP was included. These adjustments were made to keep the firing rates in roughly the same range for all cases. To incorporate the effect of STP, the STP model was used to analyze the interspike intervals of the spike train received at each synaptic input, and the normalized responses were obtained. Then, $r_{\mathrm{m}} \bar{g}_{\mathrm{S}} P_{\mathrm{S}}\left(V-E_{\mathrm{S}}\right)$ was multiplied by the normalized responses during computational simulation.

\section{Results}

\section{Depression Dominates the STP at A $\delta$ Primary}

Afferent Synapses

STP was examined at primary afferent synapses by whole-cell patch-clamp recording. A total of $41 \mathrm{DH}$ neurons that had A $\delta$-fiber synaptic input were stably recorded in our experiments. To estimate the viability of the recorded neurons, we observed their resting membrane potential and amplitude of action potential under current-clamp mode after the establishment of whole-cell recording. The recorded DH neurons satisfied the following criteria: resting membrane potential more negative than $-55 \mathrm{mV}$ and the amplitude of action potential $>60 \mathrm{mV}[19,41]$. EPSCs evoked by the stimulation of dorsal roots were recorded from $\mathrm{DH}$ neurons, and could be blocked by an AMPA receptor antagonist, CNQX $(5 \mu \mathrm{M})$. These results are consistent with early studies $[20,30]$.
Figure 1 shows $A \delta$-fiber synaptic responses evoked in a $\mathrm{DH}$ neuron by $10-\mathrm{Hz}$ stimulus trains applied on the dorsal root. Monosynaptic EPSCs clearly depressed during the course of $10-\mathrm{Hz}$ stimulus train (fig. la right, c) and recovered during the 2-min intervals between the repetitions of stimulus train (fig. la left, b). To quantify the process of synaptic plasticity, we calculated in figure $1 c$ the normalized amplitudes of ten EPSCs in one record shown in figure 1a right, i.e. the ratio of each EPSC's amplitude to the first EPSC's amplitude. The amplitude of EPSC decreased to about 0.6 at the end of $10-\mathrm{Hz}$ stimulation. To fully characterize the STP at A $\delta$ primary afferent synapses, we show in figure 2 the curves of normalized EPSC amplitudes obtained from a DH neuron under 10-pulse stimulation at different rates $(0.5,1,2,5$, $10,20 \mathrm{~Hz}$ ). Figure $2 \mathrm{a}-\mathrm{c}$ give the single-sweep EPSC records under 10-pulse stimulation at $0.5,5$ and $20 \mathrm{~Hz}$, respectively. Figure $2 \mathrm{~d}$ displays the complete curves of normalized EPSC amplitudes obtained under 10-pulse stimulation at six rates. It can be seen that EPSCs became more depressed with the increasing stimulus rate. R2, R3 and Rtail were used in figure $2 \mathrm{~d}$ to mark the second, third and the last three responses, respectively. Here, the averages of Rtail data represented the steady-state depression at each stimulus rate, while the amplitudes of R2 and R3 captured the shapes of the initial depression curves [32, 42]. In figure 2e, the semi-logarithmic plotting of the three normalized response values against stimulus rate provided a convenient description of the curves for different stimulus rates. It can be seen that R2, R3 and Rtail curves exhibited clear decline with the increasing stimulus rate. Note that the normalized R2 data correspond to the paired-pulse ratio of STP mentioned in early studies, and the normalized Rtail data correspond to the steadystate ratio of STP $[4,5,42]$. In our experiments, synaptic depression could be detected in the synaptic responses of all the recorded DH neurons. These results indicate that depression dominates the STP at A $\delta$ primary afferent synapses in spinal $\mathrm{DH}$.

To avoid polysynaptic EPSCs that often occurred after stimulation in the presence of bicuculline, we did not block the inhibitory synaptic transmission in most experiments. It is possible that the apparent depression of excitatory synaptic response could actually reflect the enhancement of inhibitory responses or the activation of presynaptic inhibitory pathways $[43,44]$. During the whole-cell recording, the existence of inhibitory postsynaptic currents (IPSCs) could be detected by adjusting the holding potential. In our experiments, the recording was terminated if IPSCs could be clearly evoked by the stimu- 
Fig. 1. A $\delta$-fiber synaptic responses evoked in a $\mathrm{DH}$ neuron by the stimulation of dorsal root. a Superimposed individual responses to the first pulse in each $10-\mathrm{Hz}$ stimulus train applied on the dorsal root (left; $\mathrm{n}=7$ repetitions) and superimposed individual responses to each pulse in one $10-\mathrm{Hz}$ stimulus train (right). Note that the bumps in the decay of EPSCs might be polysynaptic EPSCs evoked by stimulating the dorsal root or spontaneous EPSCs. b Amplitudes of the first EPSCs in seven trains shown in the left of $\mathbf{a}$. The amplitudes were normalized by the amplitude of the first EPSC in the first train. c Amplitudes of ten EPSCs in one train shown in the right of $\mathbf{a}$. The amplitudes were normalized by the amplitude of the first EPSC in this train.
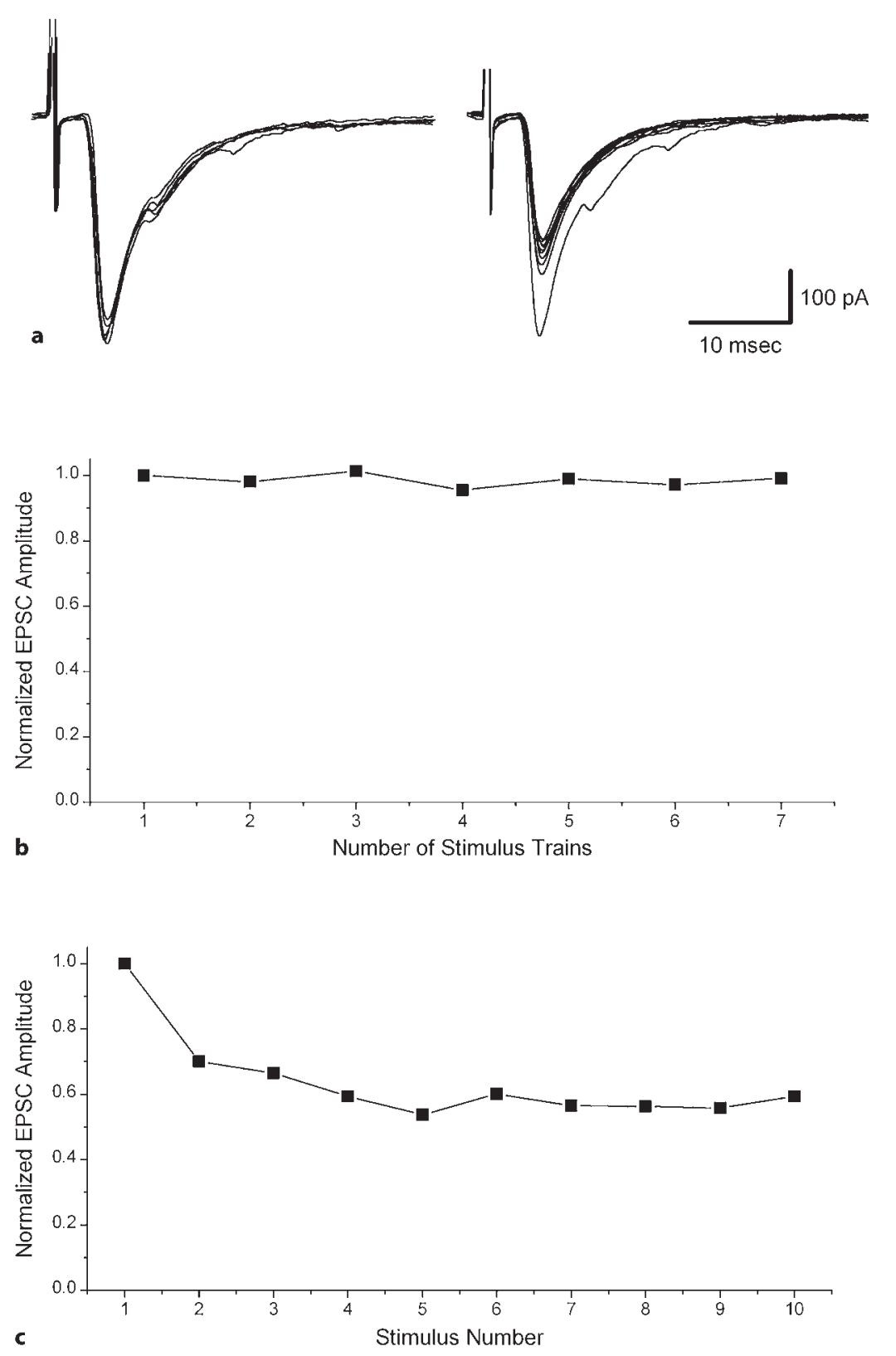

lation. Moreover, we also recorded monosynaptic EPSCs in the presence of bicuculline $(20 \mu \mathrm{M}$; a GABA $\mathrm{A}$ receptor blocker), and the curves of STP observed during the blockage of inhibition were similar to those observed under control condition (fig. 3a). Statistic analyses showed that for all five recorded neurons, there were no significant differences in the amplitudes of R2, R3 and Rtail between the experimental data recorded before and after the pharmacological manipulation ( $p>0.05$; independent $t$ test). These results indicate that the observed STP is not due to $\mathrm{GABA}_{\mathrm{A}}$ receptor-mediated presynaptic inhibition or inhibitory responses.

AMPA receptor desensitization is another possible mechanism of the STP we observed $[4,5]$. CTZ $(50 \mu \mathrm{M}$; an inhibitor of AMPA receptor desensitization) was applied to test whether AMPA receptor desensitization was 


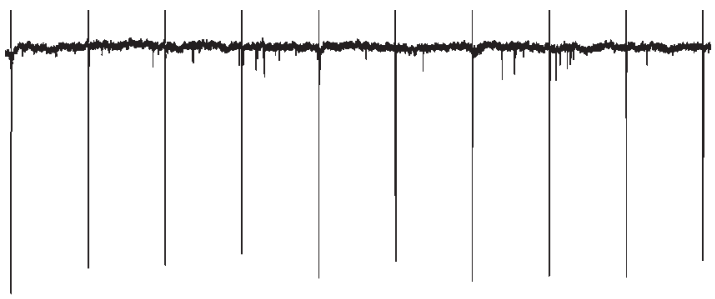

a
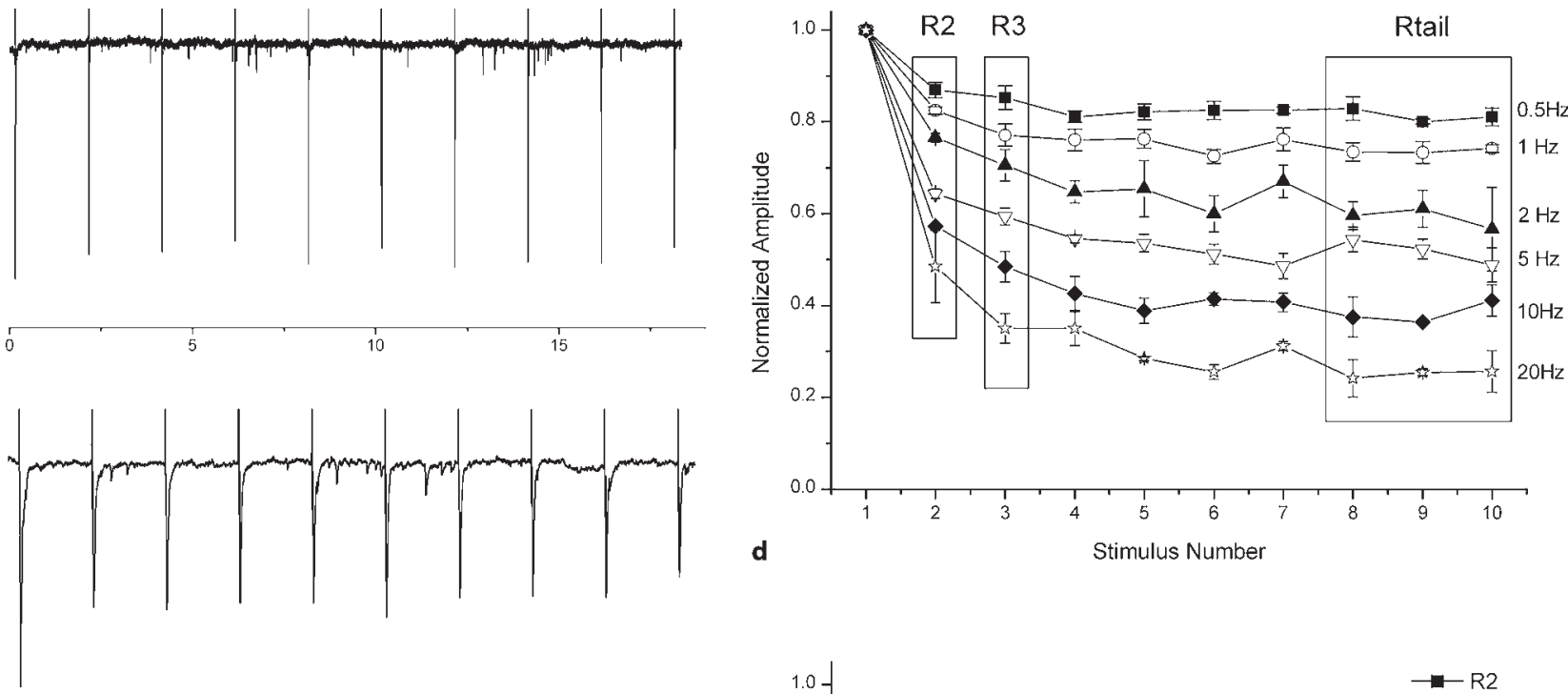

d

b 0.0

0.5

1.0

1.5

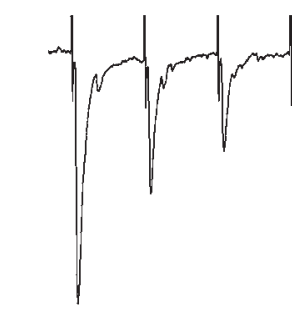

nom

$\mid 50 \mathrm{pA}$

c 0

0.1

0.2

0.3

0.4

Time (sec)

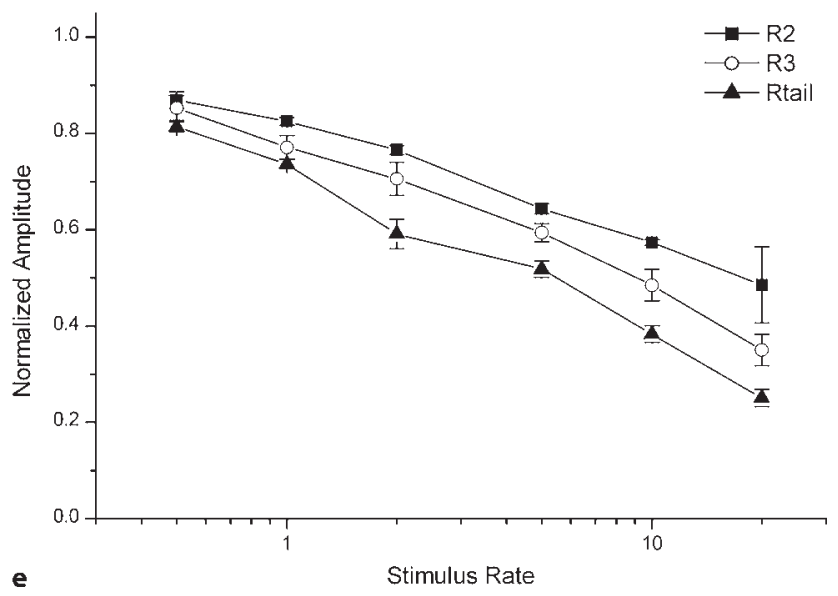

Fig. 2. An example of short-term plasticity of EPSCs recorded from a DH neuron under 10-pulse stimulation at different rates. a Monosynaptic EPSCs recorded under 10-pulse stimulation at $0.5 \mathrm{~Hz}$. b EPSCs recorded under 10 -pulse stimulation at $5 \mathrm{~Hz}$. c EPSCs recorded under the 10-pulse stimulation at $20 \mathrm{~Hz}$. d Complete curves of normalized EPSC amplitudes obtained under 10-pulse stimulation at different rates $(0.5,1,2,5,10,20 \mathrm{~Hz})$. e Normalized amplitudes of R2, R3 and Rtail in this neuron. The amplitudes are plotted against logarithm of stimulus rate. Error bars in $\mathbf{d}$ and $\mathbf{e}$ indicate the SE of experimental EPSC data.

involved in the present observation. Although CTZ could markedly prolong the duration and slightly increase the amplitude of individual responses, the curve of STP at primary afferent synapses did not show a clear change in the presence of CTZ (fig. 3b). For all five recorded neurons, no significant differences were found in the amplitudes of R2, R3 and Rtail between control and CTZ data ( $p>0.05$; independent $t$ test). These results show that the observed STP does not arise from postsynaptic receptor desensitization. In addition, in order to rule out the possible influence from postsynaptic NMDA receptor, we added AP-5 (100 $\mu \mathrm{M}$; a NMDA receptor blocker) into bathing ACSF and found no clear changes in the STP curves (fig. 3c). Statistic analyses showed that for all four recorded neurons, there were no significant differences in the amplitudes of R2, R3 and Rtail between control and AP-5 data ( $p>0.05$; independent $t$ test). 


\section{Experimental Data Can Be Fit with a Presynaptic Model of STP}

In order to study the role of the intrinsic STP properties in information processing, a method was needed of quantitatively characterizing the STP at primary afferent synapses. Here, we used a STP model system that is based on presynaptic mechanism to fit the recorded EPSC data. The model was defined by equations 1-10 in the Methods. It is well known that enhancement and depression can coexist during synaptic transmission, and that simple depletion model is usually insufficient to explain the observed STP [32, 34, 36, 37]. So we compared experimental data with expectations from a series of eight models of increasing complexity. Of eight models, four had one compartment, called $N$ (perhaps representing a pool of readily releasable synaptic vesicles), while the other four had two compartments, $N$ and $S$ (perhaps representing a pool of release-ready synaptic release sites). One- or two-compartment models had no additional processes (simple depletion), or $P$ process, or $M$ process, or both $P$ and $M$ processes. $P$ process simulated the effect of facilitation, and $M$ process the enhanced recovery process from depression during repeated activity. The two-compartment model including both $P$ and $M$ processes, referred to as the full model in the following parts, were defined by a maximum of seven parameters.

Table 1 and figure 4 show the fit of the synaptic model to all the EPSC data shown in figure 2. When matched against the experimental data, the simple depletion model with one compartment produced a large RMS error (8.82\%; table 1). The two-compartment simple depletion model produced a smaller RMS error (6.55\%; table 1). Incorporating $P$ process into one- and two-compartment models did not clearly reduce the RMS errors of data fits, while the inclusion of $M$ process markedly improved the data fits (table 1). The best fit to the experimental EPSC data was obtained with the full model, i.e. the two-compartment model including both $P$ and $M$ processes, with

Fig. 3. Effects of pharmacological manipulations on synaptic responses under $5-\mathrm{Hz}$ stimulation. a Effect of $20 \mu \mathrm{M}$ bicuculline on synaptic responses under $5-\mathrm{Hz}$ stimulation. b Effect of $50 \mu \mathrm{M}$ $\mathrm{CTZ}$ on responses under $5-\mathrm{Hz}$ stimulation. $\mathbf{c}$ Effect of $100 \mu \mathrm{M}$ AP5 on responses under $5-\mathrm{Hz}$ stimulation. In a-c, synaptic responses were recorded from a DH neuron before and after pharmacological manipulations. Insets show the responses to the first stimulus in one train before (solid line) and after (dashed line) pharmacological manipulations. Error bars in a-c indicate the SE of experimental EPSC data.
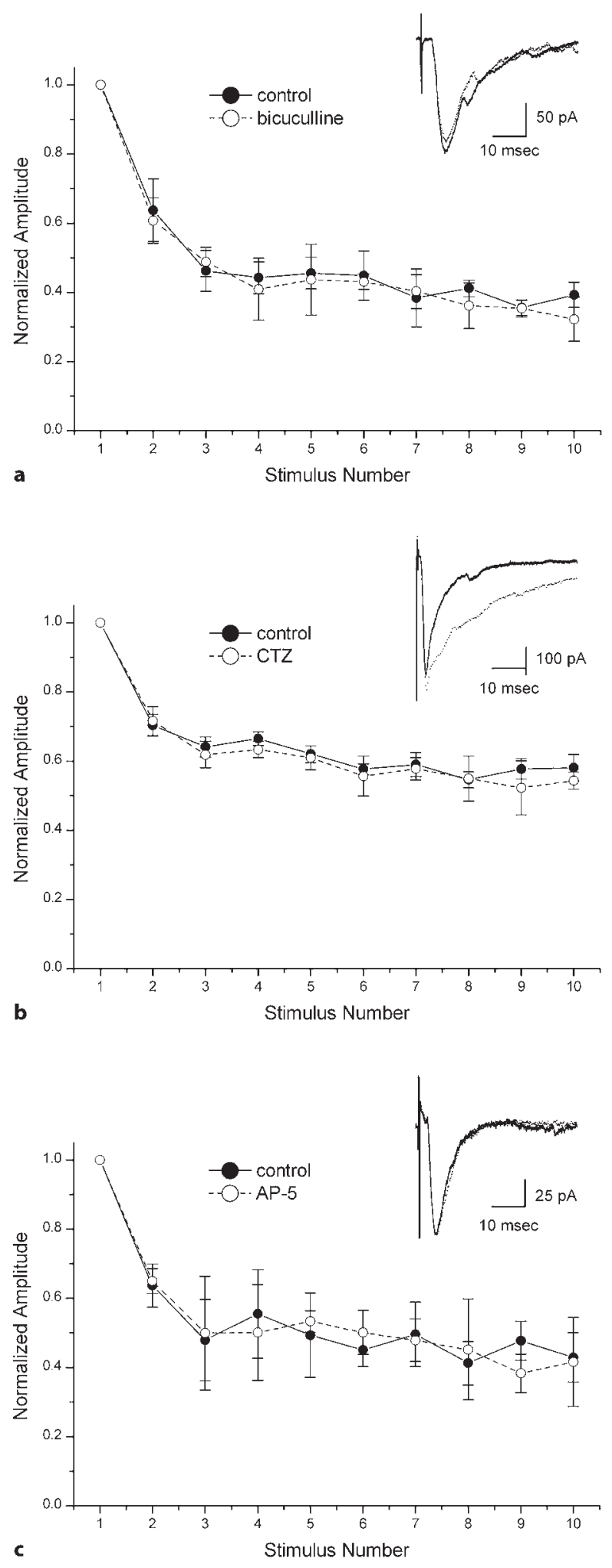
Fig. 4. Best model fit to the experimental EPSC data shown in figure 2. a Best fit curves to all the EPSC data shown in figure 2. b R2, R3 and Rtail data from the best modal fit and experiment. They are plotted against logarithm of stimulus rate. Error bars indicate the SE of experimental EPSC data. In $\mathbf{a}$ and $\mathbf{b}$, the fit was obtained with the full model, with total RMS error $2.58 \%$.
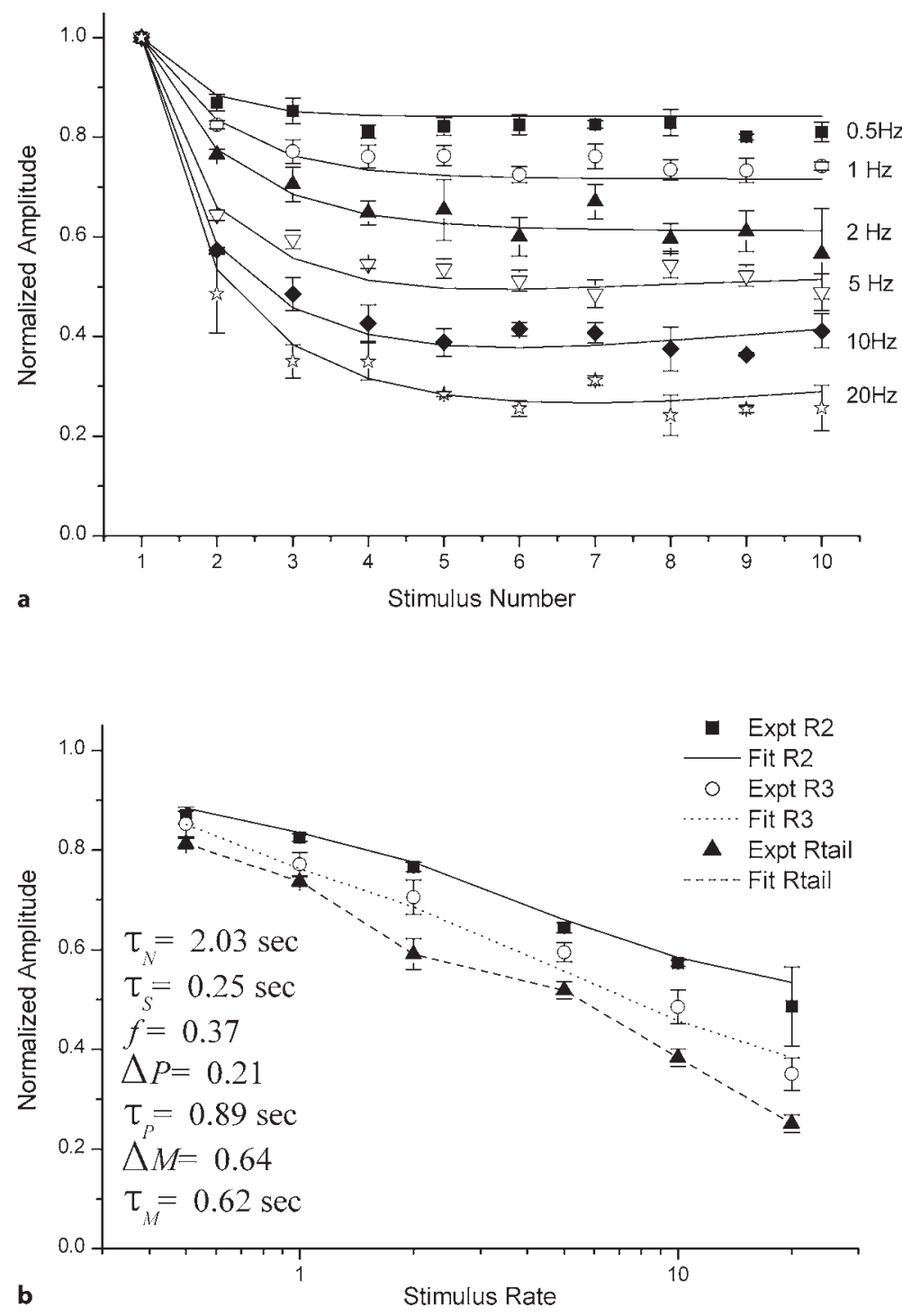

Table 1. RMS errors of eight models' best fits to EPSC data shown in figure 2

\begin{tabular}{lll}
\hline Model & One compartment & Two compartments \\
\hline Depletion & $8.82 \%$ & $6.55 \%$ \\
Depletion + P & $8.83 \%$ & $6.48 \%$ \\
Depletion + M & $3.89 \%$ & $2.61 \%$ \\
Depletion + P + M & $3.87 \%$ & $2.58 \%$ \\
\hline
\end{tabular}

Short-Term Plasticity at Primary Afferent Synapse total RMS error $2.58 \%$ (table 1). Figure 4a shows the best fit curves to all the EPSC data shown in figure 2 with the full model, and the values of parameters are shown in figure $4 \mathrm{~b}$. To further compare the eight models, we also fit the experimental EPSC data recorded under different conditions. As shown in figure 5, two-compartment models produced smaller RMS errors than one-compartment models did. Adding $M$ process to one- and two-compartment models could markedly improve the data fits, and the best fits to these experimental data were obtained with the full model (fig. 5). These results show that the full

Neurosignals 2006-07;15:74-90 
model of STP can quantitatively characterize the dynamic synaptic transmission between A $\delta$-PAFs and DH neurons under regular stimulation. The model analyses also suggest the coexistence of enhancement and depression at A $\delta$ primary afferent synapses.

In the above, we fit the experimental data recorded under regular stimulation, and the best fits from the full model were satisfactory. Under in vivo condition, spike trains are usually irregular and random, and there has been considerable interest in examining short-term synaptic changes under random stimulation [33-35, 45]. In figure 6, we used the full model to fit the EPSC data recorded under $20 \mathrm{~s}$ random stimulation with Poisson-distributed pulses whose mean rate is $4 \mathrm{~Hz}$. It can be seen that the best fit from the full model, with RMS error $4.06 \%$, accurately captures the overall time course of STP. The values of parameters are given in figure 6a. Similar fit results were obtained for EPSCs recorded from five neurons. These results demonstrate that the full model can rather accurately describe the temporal transfer characteristics of primary afferent synapses under random stimulation.

\section{Changes in $\left[\mathrm{Ca}^{2+}\right]_{o}$ Influence the STP at Primary}

Afferent Synapses

Changing extracellular $\mathrm{Ca}^{2+}$ concentration, $\left[\mathrm{Ca}^{2+}\right]_{0}$, is one of the commonest ways to affect transmitter release $[4,5]$. To further determine whether the observed STP depended on presynaptic release, we examined the effects of changing $\left[\mathrm{Ca}^{2+}\right]_{0}$ on the STP at primary afferent synapses. When $\left[\mathrm{Ca}^{2+}\right]_{0}$ was decreased from 2.4 to $0.8 \mathrm{mM}$ without changing $\left[\mathrm{Mg}^{2+}\right]_{0}$, the average amplitude of EPSCs was reduced from $281.35 \pm 85.85$ to $198.84 \pm$ $47.09 \mathrm{pA}$ ( $\mathrm{n}=7$ neurons), and synaptic responses exhibited less depression at all stimulus rates (fig. $7 \mathrm{a}-\mathrm{c}$ ). On the contrary, when $\left[\mathrm{Ca}^{2+}\right]_{\mathrm{o}}$ was increased from 2.4 to $4.0 \mathrm{mM}$, the average amplitude of EPSCs was raised from 347.13 \pm 111.68 to $374.01 \pm 119.22 \mathrm{pA}(\mathrm{n}=6$ neurons), and synaptic responses showed greater depression (fig. $7 \mathrm{~d}-\mathrm{f}$ ). It can also be seen that changes in $\left[\mathrm{Ca}^{2+}\right]_{0}$ exerted a greater effect on R2 and R3 than on Rtail (fig. 7). Statistic analysis showed that the R2, R3 and Rtail had significantly less depression under low $\left[\mathrm{Ca}^{2+}\right]_{\mathrm{o}}$ condition $(\mathrm{p}<0.05$; twoway ANOVA). The R2 and R3 had significantly greater depression under high $\left[\mathrm{Ca}^{2+}\right]_{\mathrm{o}}$ condition $(\mathrm{p}<0.05$; twoway ANOVA), while the Rtail did not have significantly greater depression under high $\left[\mathrm{Ca}^{2+}\right]_{o}$ condition $(\mathrm{p}>$ 0.05; two-way ANOVA). These results suggest that STP at A $\delta$ primary afferent synapses is of presynaptic origin and depends on transmitter release.

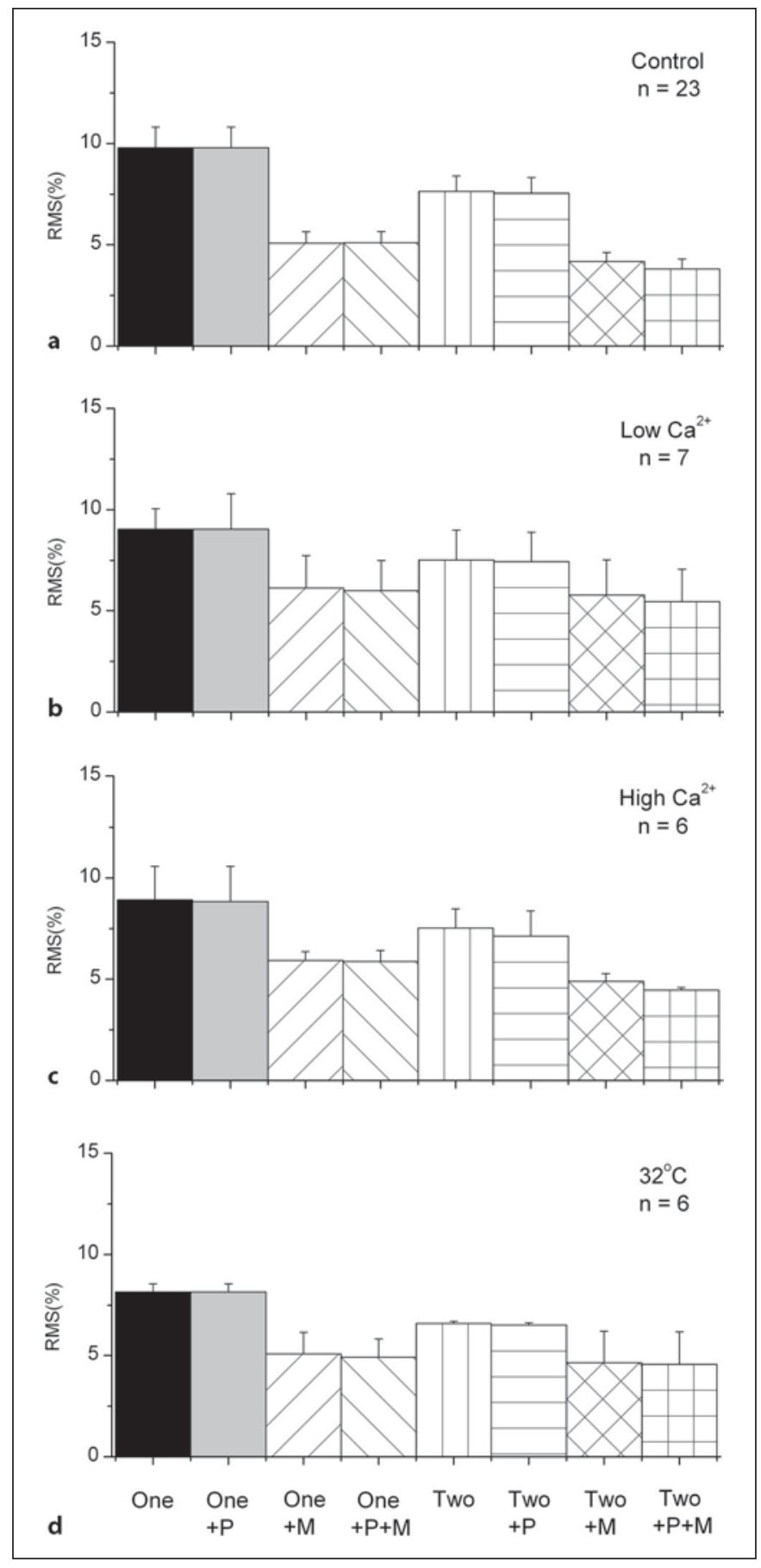

Fig. 5. Model fits to the experimental EPSC data recorded under different conditions. a Model fits to the experimental data recorded under control condition, i.e. at $24^{\circ} \mathrm{C}$ with $\left[\mathrm{Ca}^{2+}\right]_{o} 2.4 \mathrm{mM}$. b Model fits to the experimental data recorded under low $\left[\mathrm{Ca}^{2+}\right]_{\mathrm{o}}$ condition, i.e. at $24^{\circ} \mathrm{C}$ with $\left[\mathrm{Ca}^{2+}\right]_{\mathrm{o}} 0.8 \mathrm{mM}$. c Model fits to the experimental data recorded under high $\left[\mathrm{Ca}^{2+}\right]_{\mathrm{o}}$ condition, i.e. at $24^{\circ} \mathrm{C}$ with $\left[\mathrm{Ca}^{2+}\right]_{\mathrm{o}} 4.0 \mathrm{mM}$. d Model fits to the experimental data recorded under higher temperature condition, i.e. at $32^{\circ} \mathrm{C}$ with $\left[\mathrm{Ca}^{2+}\right]_{\mathrm{o}} 2.4 \mathrm{mM}$. Error bars indicate the SE of the fit errors associated with each modal. 
Fig. 6. Model fit to the EPSC data recorded from a DH neuron under random stimulation. a Average normalized amplitudes (lines; $\mathrm{n}=6$ repetitions) of EPSC data recorded from a DH neuron under random stimulation. Stimulus train was Poissondistributed with a mean rate of $4 \mathrm{~Hz}$. Dots denote the best fit to experimental data from the full model, with RMS error $4.06 \%$. b Difference between the experimental data and the model results.

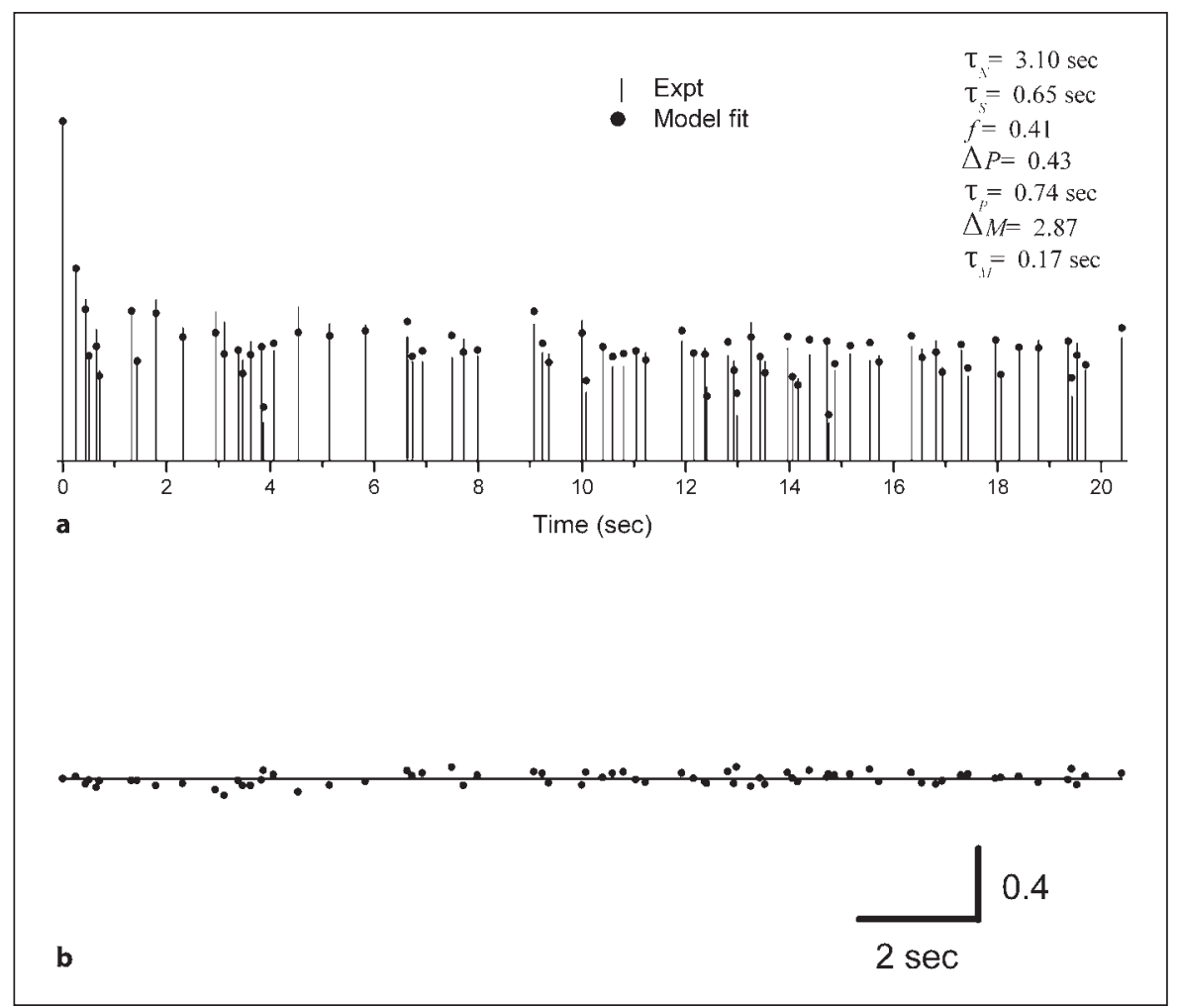

To suggest the possible mechanism underlying the effects of changing $\left[\mathrm{Ca}^{2+}\right]_{0}$ on the STP at primary afferent synapses, we fit the experimental data recorded under control and altered $\left[\mathrm{Ca}^{2+}\right]_{0}$ conditions with the full model. Because the fractional release, $f$, and the increments $\Delta P$ and $\Delta M$ are associated with $\mathrm{Ca}^{2+}$ entry during synaptic activation, these parameters were predicted to exhibit the alterations with changes in $\left[\mathrm{Ca}^{2+}\right]_{\mathrm{o}}$. To make statistic analysis, we separately fit the data sets $(n=7$, for low $\left[\mathrm{Ca}^{2+}\right]_{0} ; n=6$, for high $\left[\mathrm{Ca}^{2+}\right]_{0}$ ) with all seven parameters free to vary and analyzed the extracted values of parameters. All four time constants $\left(\tau_{N}, \tau_{\mathcal{S}}, \tau_{P}, \tau_{M}\right)$ exhibited no significant changes under altered $\left[\mathrm{Ca}^{2+}\right]_{0}$ conditions $(\mathrm{p}>$ 0.05 ; paired $\mathrm{t}$ test), but the values of $f, \Delta P$ and $\Delta M$ were significantly decreased or increased under altered $\left[\mathrm{Ca}^{2+}\right]_{0}$ conditions ( $p<0.05$; paired $t$ test). Tables 2 and 3 , together with figure $9 \mathrm{a}$, give the fit results to average data recorded under control and altered $\left[\mathrm{Ca}^{2+}\right]_{o}$ conditions. Control data were fit, with all seven parameters free to vary (tables 2, 3; Control column); altered $\left[\mathrm{Ca}^{2+}\right]_{0}$ data were fit under two conditions: with all seven parameters free to vary (tables 2, 3; Free column) and with four time constants fixed to their values found for control data (tables 2, 3; Constrained column). When all parameters were free to vary, four time constants extracted from the control and altered $\left[\mathrm{Ca}^{2+}\right]_{\mathrm{o}}$ data changed little (tables 2, $3)$. When four time constants were fixed to their control values, the extracted values of $f, \Delta P$ and $\Delta M$ were decreased for low $\left[\mathrm{Ca}^{2+}\right]_{\mathrm{o}}$ and increased for high $\left[\mathrm{Ca}^{2+}\right]_{\mathrm{o}}$ (tables 2, 3, fig. 9a). Figure 7 shows the free fit to control data and the constrained fits to altered $\left[\mathrm{Ca}^{2+}\right]_{0}$ data. These results suggest the possible mechanism underlying the effects of changing $\left[\mathrm{Ca}^{2+}\right]_{0}$ on the STP between A $\delta$ PAFs and spinal DH neurons.

\section{Change in Temperature Influences the STP at Primary Afferent Synapses}

As in most slice studies, our experiments were carried out at room temperature (about $24^{\circ} \mathrm{C}$ ). It has been reported that temperature can markedly influence synaptic transmission $[32,45,46]$, suggesting that the characteristics of STP at room temperatures are different from those at physiological temperatures. In order to more accurately explore the biological function of the observed STP, we examined the effect of changing the bath temperature on the STP. When the bath temperature was increased from 24 to $32^{\circ} \mathrm{C}$, the average amplitude of EPSCs was reduced from $290.62 \pm 45.05$ to $253.03 \pm 42.46 \mathrm{pA}$ 


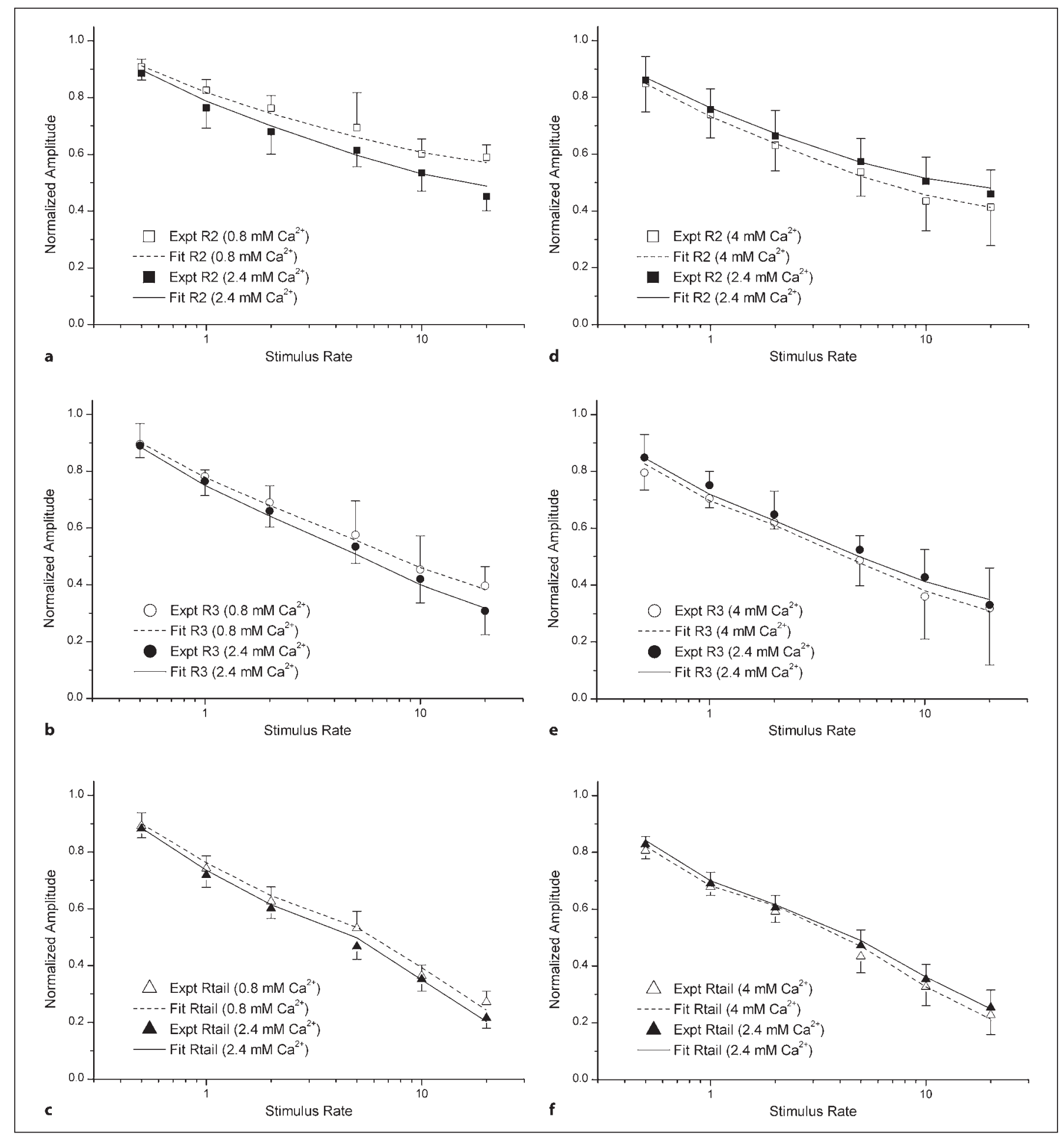

Fig. 7. Effects of changing $\left[\mathrm{Ca}^{2+}\right]_{o}$ on the STP at primary afferent synapses. a-c Effect of low $\left[\mathrm{Ca}^{2+}\right]_{0}$ on the STP at primary afferent synapses ( $\mathrm{n}=7$ neurons). $\mathbf{d - f}$ Effect of high $\left[\mathrm{Ca}^{2+}\right]_{\mathrm{o}}$ on the STP ( $n=6$ neurons). In a-f, R2, R3 and Rtail data were plotted against logarithm of stimulus rate. Solid symbols stand for the average normalized amplitudes of EPSC data recorded under control condition, and open symbols under altered $\left[\mathrm{Ca}^{2+}\right]_{\mathrm{o}}$ conditions. Solid

lines indicate the fits to control data from the full model, with all seven parameters free to vary; dashed lines indicate the fits to altered $\left[\mathrm{Ca}^{2+}\right]_{\mathrm{o}}$ data from the full model, with four time constants fixed to their values found for control data. The values of parameters used for a-c were shown in table 2 , and the values of parameters used for $\mathbf{d}-\mathbf{f}$ in table 3 . 


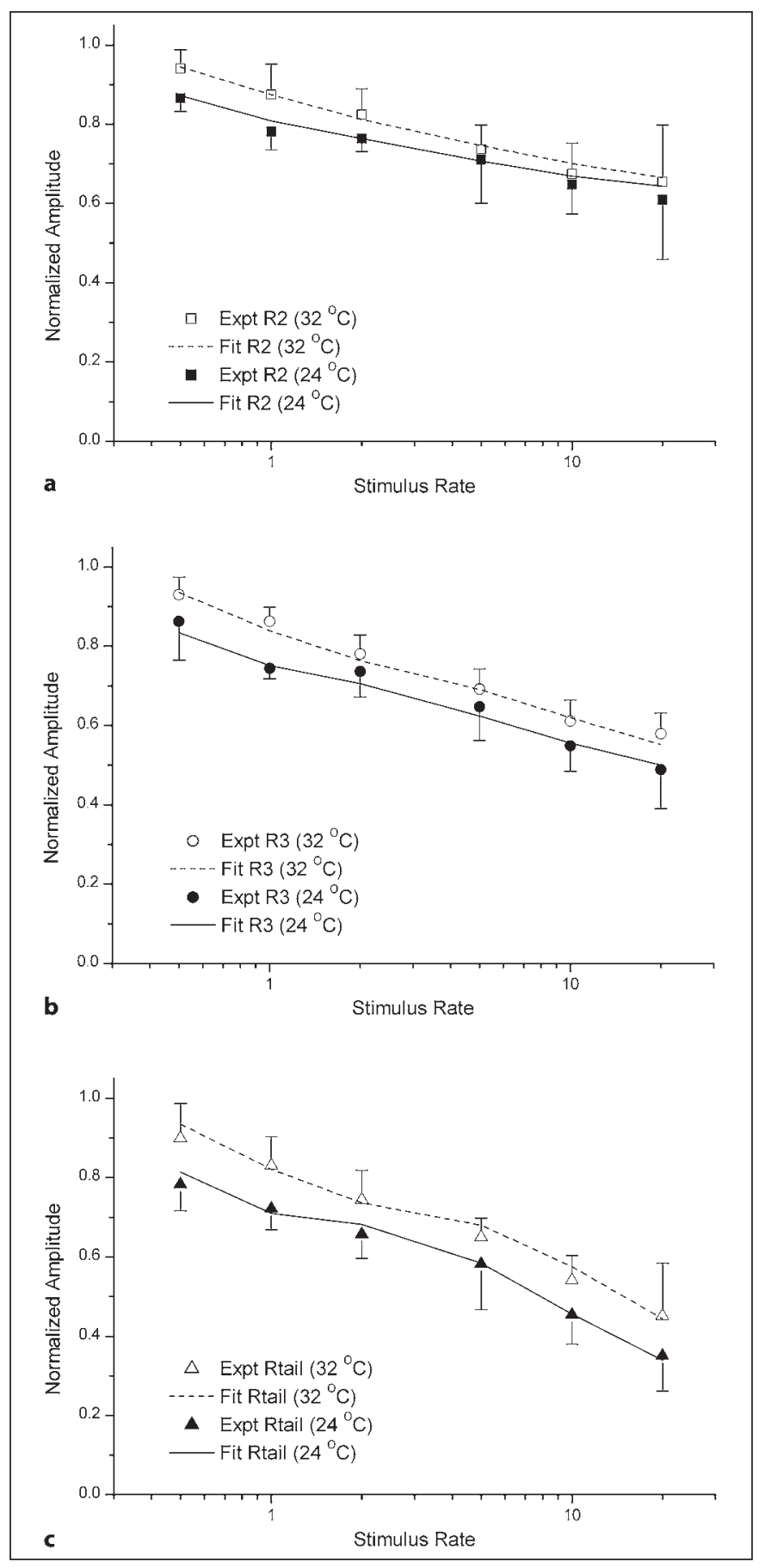

Fig. 8. Effect of change in temperature on the STP at primary afferent synapses. R2, R3 and Rtail data were plotted against logarithm of stimulus rate in $\mathbf{a}, \mathbf{b}$ and $\mathbf{c}$, respectively. In $\mathbf{a}, \mathbf{b}$ and $\mathbf{c}$, solid symbols represent the average normalized amplitudes ( $\mathrm{n}=$ 6 neurons) of EPSC data recorded under control condition, and open symbols under $32^{\circ} \mathrm{C}$ condition. Solid lines indicate the fit to control data from the full model, with all seven parameters free to vary; dashed lines indicate the fit to $32^{\circ} \mathrm{C}$ data from the full model, with $f, \Delta P$ and $\Delta M$ fixed to their values found for control data. The values of parameters were shown in table 4 .

Short-Term Plasticity at Primary Afferent Synapse
Table 2. Parameters of the model fits to experimental data recorded under control and low $\left[\mathrm{Ca}^{2+}\right]_{\mathrm{o}}$ conditions

\begin{tabular}{llcl}
\hline Parameter & Control & Constrained & Free \\
\hline$\left[\mathrm{Ca}^{2+}\right]_{\mathrm{o}}, \mathrm{mM}$ & 2.4 & 0.8 & 0.8 \\
$\tau_{\mathrm{N}}, \mathrm{s}$ & 1.30 & {$[1.30]$} & 1.64 \\
$\tau_{\mathrm{S}}, \mathrm{s}$ & 0.58 & {$[0.58]$} & 0.57 \\
$f$ & 0.49 & 0.41 & 0.40 \\
$\Delta P$ & 0.64 & 0.52 & 0.53 \\
$\tau_{\mathrm{P}}, \mathrm{s}$ & 0.54 & {$[0.54]$} & 0.68 \\
$\Delta M$ & 1.56 & 1.52 & 1.43 \\
$\tau_{\mathrm{M}}, \mathrm{s}$ & 0.28 & {$[0.28]$} & 0.31 \\
$\mathrm{RMS}$ error, \% & 2.12 & 3.23 & 2.83 \\
\hline
\end{tabular}

Table 3. Parameters of the model fits to experimental data recorded under control and high $\left[\mathrm{Ca}^{2+}\right]_{\mathrm{o}}$ conditions

\begin{tabular}{llcl}
\hline Parameter & Control & Constrained & Free \\
\hline$\left[\mathrm{Ca}^{2+}\right]_{\mathrm{o}}, \mathrm{mM}$ & 2.4 & 4 & 4 \\
$\tau_{\mathrm{N}}, \mathrm{s}$ & 1.82 & {$[1.82]$} & 1.97 \\
$\tau_{\mathrm{S}}, \mathrm{s}$ & 0.61 & {$[0.61]$} & 0.64 \\
$f$ & 0.36 & 0.42 & 0.41 \\
$\Delta P$ & 0.08 & 0.09 & 0.11 \\
$\tau_{\mathrm{P}}, \mathrm{s}$ & 0.42 & {$[0.42]$} & 0.34 \\
$\Delta M$ & 3.30 & 4.38 & 4.10 \\
$\tau_{\mathrm{M}}, \mathrm{s}$ & 0.37 & {$[0.37]$} & 0.44 \\
$\mathrm{RMS}$ error, \% & 2.30 & 2.39 & 2.28 \\
\hline
\end{tabular}

( $\mathrm{n}=6$ neurons). As shown in figure 8 , with the increasing bath temperature, synaptic responses exhibited less depression at all stimulus rates. Statistic analysis showed that the R2, R3 and Rtail had significantly less depression under $32^{\circ} \mathrm{C}$ condition ( $<<0.05$; two-way ANOVA). We fit the experimental data recorded under control and $32^{\circ} \mathrm{C}$ conditions with the full model. Increased bath temperature was expected to mainly affect the time constants: $\tau_{N}, \tau_{S}, \tau_{P}, \tau_{M}[32]$. To make statistic analysis, we separately fit the data sets $(n=6)$ with all seven parameters free to vary and analyzed the extracted values of parameters. The values of $f, \Delta P$ and $\Delta M$ exhibited no significant changes under $32^{\circ} \mathrm{C}$ condition ( $p>0.05$; paired t-test), but all four time constants were significantly decreased under $32^{\circ} \mathrm{C}$ condition ( $\mathrm{p}<0.05$; paired $\mathrm{t}$ test). Table 4 , together with figure $9 \mathrm{~b}$, gives the fit results to average data recorded under control and $32^{\circ} \mathrm{C}$ conditions. When all parameters were free to vary, the values 
Table 4. Parameters of the model fits to experimental data recorded at different temperatures with $\left[\mathrm{Ca}^{2+}\right]_{\mathrm{o}}=2.4 \mathrm{mM}$

\begin{tabular}{lccc}
\hline Parameter & Baseline & Constrained & Free \\
\hline Temperature, ${ }^{\circ} \mathrm{C}$ & 24 & 32 & 32 \\
$\tau_{\mathrm{N}}, \mathrm{s}$ & 2.64 & 1.30 & 1.60 \\
$\tau_{\mathrm{S}}, \mathrm{s}$ & 0.69 & 0.34 & 0.44 \\
$f$ & 0.25 & {$[0.25]$} & 0.21 \\
$\Delta P$ & 0.10 & {$[0.10]$} & 0.08 \\
$\tau_{\mathrm{P}}, \mathrm{S}$ & 0.50 & 0.15 & 0.17 \\
$\Delta M$ & 5.97 & {$[5.97]$} & 4.43 \\
$\tau_{\mathrm{M}}, \mathrm{S}$ & 0.36 & 0.21 & 0.27 \\
$\mathrm{RMS}$ error, \% & 3.04 & 2.80 & 2.71 \\
\hline
\end{tabular}

of $f, \Delta P$ and $\Delta M$ extracted from the control and $32^{\circ} \mathrm{C}$ data changed little (table 4, Control and Free columns). When the values of $f, \Delta P$ and $\Delta M$ were fixed to their control values, the extracted time constants were clearly decreased for $32^{\circ} \mathrm{C}$ (table 4 , Constrained column, fig. 9b). Figure 8 shows the free fit to control data and the constrained fit to $32^{\circ} \mathrm{C}$ data. These results suggest the possible mechanism underlying the effect of changing temperature on the STP at primary afferent synapses.

\section{STP Enhances the Sensitivity of Neuron to Rate}

\section{Changes in Synaptic Inputs}

Using an integrate-and-fire model neuron that receives 1,000 synaptic inputs, we studied the role of the STP at primary afferent synapses in processing neural information. Half of the model neuron's synapses receive Poisson-distributed presynaptic spike trains with mean rate $20 \mathrm{~Hz}$, and the other half with mean rate $2 \mathrm{~Hz}$ (fig. 10a). To add the effect of STP into the model, the normalized responses to the spike train at each synaptic input were obtained from the full model of STP, with $\tau_{N}=1.60 \mathrm{~s}, \tau_{S}=0.44 \mathrm{~s}, f=0.21, \Delta P=0.08, \tau_{P}=0.17 \mathrm{~s}$, $\Delta M=4.43$, and $\tau_{M}=0.27 \mathrm{~s}$. These parameter values came from the free fit to experimental data recorded at $32^{\circ} \mathrm{C}$ (table 4). Then, we multiplied $r_{\mathrm{m}} \bar{g}_{S} P_{S}\left(V-E_{S}\right)$ by the normalized response for the corresponding input at each synapse. Without STP, $50 \%$ modulation $( \pm 10 \mathrm{~Hz})$ of the rapidly-firing afferents affected the firing output of postsynaptic neuron, but $50 \%$ modulation $( \pm 1 \mathrm{~Hz})$ of the slowly-firing afferents did not (fig. 10b). In contrast, with STP, 50\% modulation of either rapidly- or slowly-firing afferents had a strong impact on the firing output of postsynaptic neuron (fig. 10c). These results indicate that STP at primary afferent synapses can enhance the sensitivity

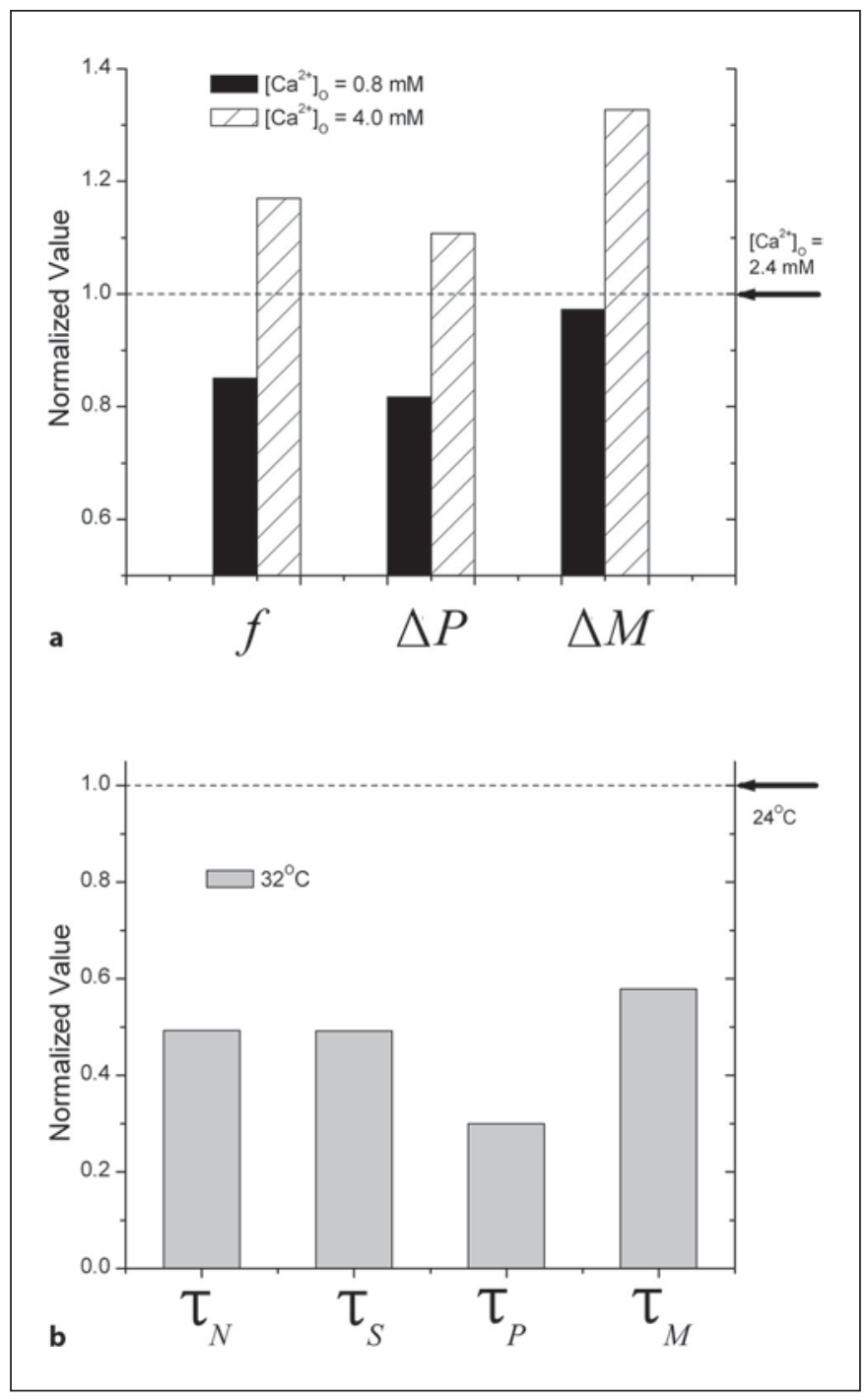

Fig. 9. Histograms of full model parameter values for the fits to experimental data recorded under different conditions. a Histograms of $f, \Delta P$ and $\Delta M$ from the constrained fits (fig. 7, tables 2 , $3)$ to altered $\left[\mathrm{Ca}^{2+}\right]_{\mathrm{o}}$ data. The values of $f, \Delta P$ and $\Delta M$ were normalized by the values found for control condition, i.e. $\left[\mathrm{Ca}^{2+}\right]_{\mathrm{o}}=$ $2.4 \mathrm{~mm}$. b Histograms of four time constants from the constrained fit (fig. 8 , table 4 ) to $32^{\circ} \mathrm{C}$ data. The values of four time constants were normalized by the values found for control condition, i.e. $24^{\circ} \mathrm{C}$.

of postsynaptic neuron to firing rate changes in the slowly-firing afferents. It should be also noted that with STP, the same $\pm 1 \mathrm{~Hz}$ modulation that strongly affected the neuronal response when it occurred on slowly-firing afferents (fig. 10c, center) had no observable effect when applied to the rapidly-firing afferents (fig. 10C, right). 


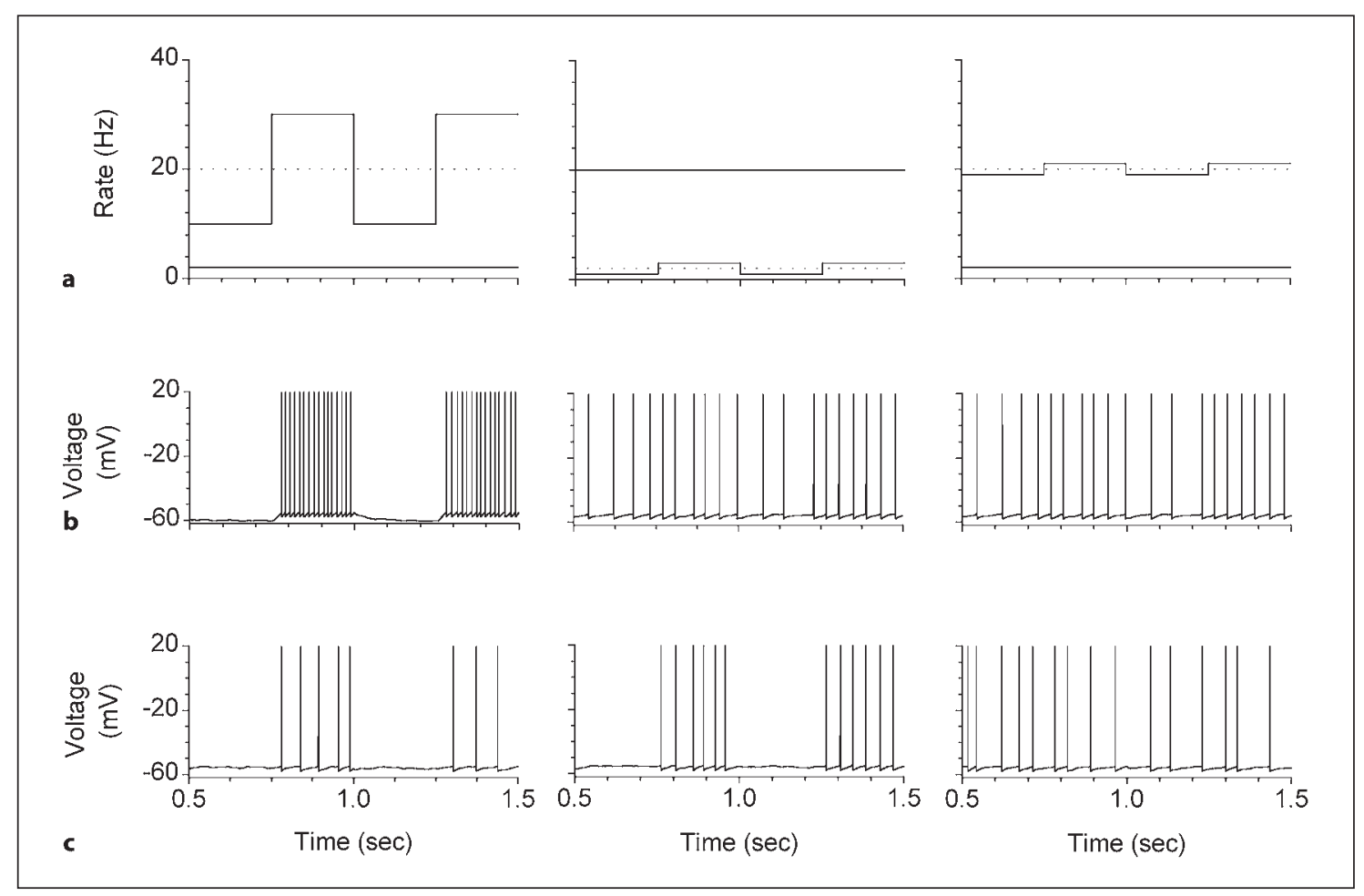

Fig. 10. Effect of the STP on the output of an integrate-and-fire model neuron with synaptic inputs. a Input rates for the two sets of synapses used to generate the responses in $\mathbf{b}$ and $\mathbf{c}$. The model neuron receives 500 synaptic inputs each with mean rate of $20 \mathrm{~Hz}$ and 500 inputs each with mean rate of $2 \mathrm{~Hz}$. In the left, the firing rates of $20-\mathrm{Hz}$ inputs are modulated by $50 \%$ while the $2-\mathrm{Hz}$ inputs are held at constant rate; in the center, $20-\mathrm{Hz}$ inputs are constant while $2-\mathrm{Hz}$ inputs are modulated by $50 \%$; in the right, $20-\mathrm{Hz}$ inputs are modulated by $\pm 1 \mathrm{~Hz}$ while $2-\mathrm{Hz}$ inputs are constant. b Reponses of the model neuron without STP to the input modulation shown in a above each panel. c Reponses of the model neuron with depression-dominated STP to the input modulation shown in a.

\section{Discussion}

\section{Main Results}

This paper presents the systematical study on the STP at primary afferent synapses between $A \delta$-PAFs and neurons in rat deep spinal $\mathrm{DH}$. Our results indicate that depression dominates the STP at A $\delta$ primary afferent synapses, and that the STP is due to presynaptic mechanism. By fitting the experimental data recorded under regular and random stimulations, we showed that the full model of STP could quantitatively characterize the STP between A $\delta$-fibers and DH neurons. Furthermore, using the STP model and a model neuron with synaptic inputs, we demonstrated that STP at primary afferent synapses could enhance the sensitivity of postsynaptic neuron to rate changes in the slowly-firing afferents. Thus, our research links the intrinsic STP properties of primary afferent synapses with their biological role in information processing.

Short-Term Plasticity at Primary Afferent Synapse

\section{Mechanism of STP at Primary Afferent Synapses}

In our research, STP at primary afferent synapses exhibited dominant depression. So what is the mechanism of this form of STP? In principle, the STP we observed could arise from a change in the amount of neurotransmitter released from presynaptic terminals, or a change in the sensitivity of postsynaptic receptors to the neurotransmitter, or other factors such as inhibitory responses. To begin with, dorsal root stimulation can possibly activate the pathways that produce presynaptic inhibition [44], which could complicate the interpretation of synaptic depression observed by us. Indeed, low-frequency depression of monosynaptic reflex in the adult rat has been attributed mainly to presynaptic inhibition [43]. It is also possible that the enhancement of inhibitory synaptic responses can cause the depression of excitatory response during repeated activity. To investigate these possibilities, we applied the $\mathrm{GABA}_{\mathrm{A}}$ receptor blocker bicuculline and measured its effect on STP. No significant 
changes were found in the curves of STP (fig. 3a). Therefore, we conclude that neither $\mathrm{GABA}_{\mathrm{A}}$ receptor-mediated presynaptic inhibition nor inhibitory responses significantly contribute to the present observations. It has been shown that the activation of presynaptic $\mathrm{GABA}_{\mathrm{B}}$ receptor can depress PAFs-evoked monosynaptic EPSCs [47]. The present study cannot determine whether $\mathrm{GABA}_{\mathrm{B}}$ receptors are involved in the observed STP at A $\delta$ primary afferent synapses. In addition, research also shows that presynaptic glutamate receptors can exert marked modulations on the synaptic transmission between PAFs and spinal DH neurons $[48,49]$. Thus, further experiments are needed to examine the effects of presynaptic $G_{A B A}$ and glutamate receptors on the STP at primary afferent synapses. Moreover, presynaptic glycine receptors have been shown to enhance glutamate release in the trapezoid body of auditory brainstem [50, 51]. It is not known whether presynaptic glycine receptors exist in spinal $\mathrm{DH}$ and whether they play a role in the STP we observed.

Secondly, AMPA receptor desensitization is a candidate mechanism of the STP we observed. It has been reported that postsynaptic receptors can become desensitized during repeated activity, thus reducing synaptic responses $[4,5]$. But we found that adding the AMPA receptor desensitization inhibitor CTZ into bathing ACSF did not significantly change the kinetics or degree of the observed STP (fig. 3b). So the change in the sensitivity of postsynaptic receptors was not significantly involved in the STP at primary afferent synapses. Thirdly, previous studies show that STP at various synapses mainly has presynaptic origin and depends on transmitter release [4-6]. If the STP observed by us is due to presynaptic mechanism, it should be influenced by the factors that affect transmitter release. In our experiments, decreasing the amount of release by lowering $\left[\mathrm{Ca}^{2+}\right]_{o}$ could reduce synaptic depression (fig. $7 \mathrm{a}-\mathrm{c}$ ). Conversely, increasing the amount of release by raising $\left[\mathrm{Ca}^{2+}\right]_{0}$ could cause greater depression (fig. $7 \mathrm{~d}-\mathrm{f}$ ). These results suggest that the STP at A $\delta$ primary afferent synapses depends on presynaptic release. Moreover, the satisfactory fits to experimental data with the presynaptic model of STP also suggest that the STP we observed is due to presynaptic mechanism.

\section{Model Fits to Experimental Data and the Nature of Model Elements}

We employed a quantitative synaptic model of STP to fit the experimental data recorded under various conditions. In the model, we assume that $N$ compartment represents the behavior of readily releasable transmitter vesicles, while $S$ compartment reflects the behavior of release sites in synaptic buttons. We found that two-compartment models provided better fits to the experimental data than one-compartment models (fig. 5, table 1). Data fits showed that in two-compartment models, $N$ compartment had a time constant $\left(\tau_{N}\right)$ of several seconds and $S$ compartment had a time constant $\left(\tau_{S}\right)$ of several hundred milliseconds. These fit results are different from those obtained from excitatory synapses on motoneurons in spinal ventral horn $[32,33]$. In their studies, both $\tau_{N}$ and $\tau_{S}$ were several seconds and much larger than ours, which means that greater depression exists in the STP at excitatory synapses on spinal motoneurons. Indeed, Li and Burke [32, 33] showed that synaptic depression could be clearly detected even under $0.125-\mathrm{Hz}$ stimulation at excitatory synapses in spinal ventral horn. The above comparison demonstrates that excitatory synapses in the different regions of spinal cord can have a great diversity in their STP.

$P$ process in the model proved compatible with the notion of 'residual calcium' [4, 32, 37, 52], in which facilitation is caused by an action of $\mathrm{Ca}^{2+}$ remaining in the nerve terminal after previous stimulus. We found that incorporating $P$ process into one- and two-compartment models did not clearly reduce the RMS errors of data fits (fig. 5, table 1). This implies that facilitation may play a minor role in STP at A $\delta$ primary afferent synapses. In addition, the time constant of $P$ process, $\tau_{P}$, was hundreds of milliseconds in our data fits. It is now known that facilitation at synapses can be subdivided into a rapid phase lasting tens of milliseconds (F1) and a slower phase lasting hundreds of milliseconds (F2) [4, 52]. Our model analyses suggest that facilitation at primary afferent synapses in spinal DH belongs to slow-delaying facilitation (F2).

$M$ process in the model simulates the enhanced recovery process from depression during repeated activity [35, $36,38,39]$. In our research, the inclusion of $M$ process markedly improved the data fits (fig. 5 , table 1), suggesting that repeated presynaptic activity can increase the availability of readily releasable transmitter at primary afferent synapses. It should be noted that $M$ process was implemented by modifying $\tau_{N}$ that governs the rate of transmitter renewal, while the time constant for renewal of release sites $\tau_{S}$ was assumed to be constant. This enables the parameter extraction program to differentiate between $\tau_{N}$ and $\tau_{S}$, in spite of their analogous effects on the calculated responses.

\section{Functional Significance}

Early research indicates that STP takes a key part in processing information in neuronal networks $[1,7,8]$. Here, we studied the function of the STP at primary af- 
ferent synapses with a model neuron receiving synaptic inputs. The full model of STP was employed to describe the temporal transfer characteristics of primary afferent synapses. We found that with STP depressing the postsynaptic responses to rapidly-firing afferents, postsynaptic neurons can detect rate changes in both rapidly- and slowly-firing afferents with equal sensitivity. A network composed of such synapses can become sensitive to rate changes in slowly-firing inputs that would otherwise be swamped by the EPSPs originating from more rapidlyfiring inputs. Moreover, $\pm 1 \mathrm{~Hz}$ modulation that strongly affected the neuronal response when it occurred on slowly-firing afferents (fig. 10c, center) had no clear effect when applied to the rapidly-firing afferents (fig. 10c, right). This means that as well as amplifying the effect of large percentage changes on slowly-firing inputs, STP allows small percentage fluctuations of rapidly-firing inputs to be ignored. This property is important because random fluctuations of high average firing rates involve large absolute variations. Thus, our results indicate that STP at primary afferent synapses allows DH neuron to respond to relative, rather than absolute, changes in presynaptic firing rate.

An important consequence of STP is that synapses can act as filters with a wide range of properties $[1,10]$. According to our results, A $\delta$ primary afferent synapses have a rather high probability of release. With depression dominating their STP, these synapses can act as low-pass filters that are most effective at the onset of presynaptic activity. It has been also suggested that the depressing plasticity process can remove correlations most efficiently over timescales comparable to their own characteristic relaxation time constant [14]. Dominated by such mechanism, synaptic circuits between A $\delta$-PAFs and DH neurons may serve as novelty detectors by decorrelating afferent inputs and therefore function in a 'search mode'. It has been known that first pain, i.e. the immediate sharp, pricking burst of awareness of acute trauma, is signaled by type II A-fiber nociceptors through A $\delta$-fibers $[17,53]$. These nociceptors have burst activity at the onset of noxious stimulus, which is consistent with the percept of a momentary pricking sensation. However, besides an early peak frequency, the response of type II A-fiber nociceptors to noxious stimulus has a slow adaptation [53, 54], whose continuous firing may exert much interference on the discrimination between first and second pain. Based on our study, we propose that STP at A $\delta$ primary afferent synapses, with depression predominating, can greatly reduce the follow-up effect of continuous firing from peripheral nociceptors on postsynaptic DH neurons. By doing this, the plasticity process decorrelates the afferent inputs and thus contributes to the clear discrimination between first and second pain.

Furthermore, the characteristics of STP at a given synapse are not fixed. They can be adjusted through the modulation of the initial release probability or other aspects of synaptic transmission. A great many receptors are expressed on both PAFs and DH neurons [50], and STP at primary afferent synapses is ready to be modulated under in vivo conditions $[48,55]$. Consequently, neural information processing between PAFs and $\mathrm{DH}$ neurons can also be functionally modulated. The present study provides a basis for the further research on the modulation of STP at primary afferent synapses under physiological and pathological conditions, and the more detailed analysis of its function in shaping the dynamics of neuronal responses.

\section{Acknowledgements}

We thank Prof. Robert E. Burke for his generous technical support and candid advice on our research. The present study was supported by National Natural Science Foundation of China Grants 30400132 and 30530260.

\section{References}

1 Abbott LF, Regehr WG: Synaptic computation. Nature 2004;431:796-803.

12 Zucker RS: Short-term synaptic plasticity. Annu Rev Neurosci 1989;12:13-31.

3 Zucker RS: Calcium- and activity-dependent synaptic plasticity. Curr Opin Neurobiol 1999;9:305-313.

4 Zucker RS, Regehr WG: Short-term synaptic plasticity. Annu Rev Physiol 2002;64:355405.

Short-Term Plasticity at Primary Afferent Synapse
5 Blitz DM, Foster KA, Regehr WG: Shortterm synaptic plasticity: A comparison of two synapses. Nat Rev Neurosci 2004;5:630640.

6 Xu-Friedman MA, Regehr WG: Structural contributions to short-term synaptic plasticity. Physiol Rev 2004;84:69-85.

7 O’Donovan MJ, Rinzel J: Synaptic depression: A dynamic regulator of synaptic communication with varied functional roles. Trends Neurosci 1997;20:431-433.
8 Nadim F, Manor Y: The role of short-term synaptic dynamics in motor control. Curr Opin Neurobiol 2000;10:683-690.

9 Markram H, Gupta A, Uziel A, Wang Y, Tsodyks M: Information processing with frequency-dependent synaptic connections. Neurobiol Learn Mem 1998;70:101-112.

10 Fortune ES, Rose GJ: Short-term synaptic plasticity as a temporal filter. Trends Neurosci 2001;24:381-385. 
11 Silberberg G, Wu C, Markram H: Synaptic dynamics control the timing of neuronal excitation in the activated neocortical microcircuit. J Physiol 2004;556:19-27.

12 Abbott LF, Varela JA, Sen K, Nelson SB: Synaptic depression and cortical gain control. Science 1997;275:220-224.

13 Galarreta M, Hestrin S: Frequency-dependent synaptic depression and the balance of excitation and inhibition in the neocortex. Nat Neurosci 1998;1:587-594.

14 Goldman MS, Maldonado P, Abbott LF: Redundancy reduction and sustained firing with stochastic depressing synapses. J Neurosci 2002;22:584-591.

-15 Tsodyks MV, Markram H: The neural code between neocortical pyramidal neurons depends on neurotransmitter release probability. Proc Natl Acad Sci USA 1997;94:719723.

16 Cook DL, Schwindt PC, Grande LA, Spain WJ: Synaptic depression in the localization of sound. Nature 2003;421:66-70.

17 Millan MJ: The induction of pain: an integrative review. Prog Neurobiol 1999;57:1164.

18 Yoshimura M, Jessell TM: Primary afferentevoked synaptic responses and slow potential generation in rat substantia gelatinosa neurons in vitro. J Neurophysiol 1989;62:96108.

19 Yoshimura M, Jessell TM: Amino acid-mediated EPSPs at primary afferent synapses with substantia gelatinosa neurones in the rat spinal cord. J Physiol 1990;430:315-335.

20 Yoshimura M, Nishi S: Blind patch-clamp recordings from substantia gelatinosa neurons in adult rat spinal cord slices: pharmacological properties of synaptic currents. Neuroscience 1993;53:519-526.

-21 Nakatsuka T, Gu JG: ATP P2X receptor-mediated enhancement of glutamate release and evoked EPSCs in dorsal horn neurons of the rat spinal cord. J Neurosci 2001;21:65226531.

22 Willis WD, Coggeshall RE: Structure of dorsal horn; in Willis WD, Coggeshall RE (eds): Sensory Mechanisms of the Spinal Cord. New York, Plenum, 1978, pp 53-127.

23 Randic M, Jiang MC, Cerne R: Long-term potentiation and long-term depression of primary afferent neurotransmission in the rat spinal cord. J Neurosci 1993;13:52285241.

24 Sandkuhler J, Chen JG, Cheng G, Randic M: Low-frequency stimulation of afferent $A \delta$ fibers induces long-term depression at primary afferent synapses with substantia gelatinosa neurons in the rat. J Neurosci 1997;17: 6483-6491.

25 Sandkuhler J: Learning and memory in pain pathways. Pain 2000;88:113-118.
26 Wan YH, Hu SJ: Short-term depression at primary afferent synapses in rat substantia gelatinosa region. Neuroreport 2003;14:197200.

27 Wan YH, Wang YY, Dai F, Hu SJ: Visually guided patch-clamp recording of spinal dorsal horn neuron's postsynaptic current evoked by primary afferent fiber. Acta Physiol Sin 2004;56:550-557.

28 Ahmadi S, Lippross S, Neuhuber WL, Zeilhofer $\mathrm{HU}: \mathrm{PGE}_{2}$ selectively blocks inhibitory glycinergic neurotransmission onto rat superficial dorsal horn neurons. Nat Neurosci 2002;5:34-40

29 Chen J, Sandkuhler J: Induction of homosynaptic long-term depression at spinal synapses of sensory A $\delta$-fibers requires activation of metabotropic glutamate receptors. Neuroscience 2000;98:141-148.

30 Luo C, Kumamoto E, Furue H, Chen J, Yoshimura M: Nociceptin inhibits excitatory but not inhibitory transmission to substantia gelatinosa neurones of adult rat spinal cord. Neuroscience 2002;109:349-358.

31 Lev-Tov A, Pinco M: In vitro studies of prolonged synaptic depression in the neonatal rat spinal cord. J Physiol 1992;447:149-169.

32 Li Y, Burke RE: Short-term synaptic depression in the neonatal mouse spinal cord: effects of calcium and temperature. J Neurophysiol 2001;85:2047-2062.

33 Li Y, Burke RE: Developmental changes in short-term synaptic depression in the neonatal mouse spinal cord. J Neurophysiol 2002; 88:3218-3231.

34 Varela JA, Sen K, Gibson J, Fost J, Abbott LF, Nelson SB: A quantitative description of short-term plasticity at excitatory synapses in layer $2 / 3$ of rat primary visual cortex. J Neurosci 1997;17:7926-7940.

35 Dittman JS, Regehr WG: Calcium dependence and recovery kinetics of presynaptic depression at the climbing fiber to Purkinje cell synapse. J Neurosci 1998;18:6147-6162.

36 Weis S, Schneggenburger R, Neher E: Properties of a model of $\mathrm{Ca}^{++}$-dependent vesicle pool dynamics and short term synaptic depression. Biophys J 1999;77:2418-2429.

-37 Dittman JS, Kreitzer AC, Regehr WG: Interplay between facilitation, depression, and residual calcium at three presynaptic terminals. J Neurosci 2000;20:1374-1385.

-38 Stevens CF, Wesseling JF: Activity-dependent modulation of the rate at which synaptic vesicles become available to undergo exocytosis. Neuron 1998;21:415-424.

39 Wang LY, Kaczmarek LK: High-frequency firing helps replenish the readily releasable pool of synaptic vesicles. Nature 1998;394: 384-388.

40 Dayan P, Abbott LF: Theoretical Neuroscience: Computational and Mathematical Modeling of Neural Systems. London, MIT Press, 2001.
41 Schneider SP: Spike frequency adaptation and signaling properties of identified neurons in rodent deep spinal dorsal horn. J Neurophysiol 2003;90:245-258.

42 Hempel CM, Hartman KH, Wang XJ, Turrigiano GG, Nelson SB: Multiple forms of short-term plasticity at excitatory synapses in rat medial prefrontal cortex. J Neurophysiol 2000;83:3031-3041.

43 Seburn KL, Cope TC: Low-frequency depression of the monosynaptic reflex is not altered by tetrodotoxin-induced nerve conduction blockade. J Neurophysiol 1997;78: 19-23.

44 MacDermott AB, Role LW, Siegelbaum SA: Presynaptic ionotropic receptors and the control of transmitter release. Annu Rev Neurosci 1999;22:443-485.

45 Dobrunz LE, Stevens CF: Response of hippocampal synapses to natural stimulation patterns. Neuron 1999;22:157-166.

46 Pierau FR, Klee MR, Klussmann FW: Effect of temperature on postsynaptic potentials of cat spinal motoneurones. Brain Res 1976; 114:21-34.

47 Yang K, Wang D, Li YQ: Distribution and depression of the $\mathrm{GABA}_{\mathrm{B}}$ receptor in the spinal dorsal horn of adult rat. Brain Res Bull 2001; 55:479-485.

48 Huettner JE, Kerchner GA, Zhuo M: Glutamate and the presynaptic control of spinal sensory transmission. Neuroscientist 2002; 8:89-92.

49 Rustioni A: Modulation of sensory input to the spinal cord by presynaptic ionotropic glutamate receptors. Arch Ital Biol 2005; 143 : 103-112.

50 Turecek R, Trussell LO: Presynaptic glycine receptors enhance transmitter release at a mammalian central synapse. Nature 2001; 411:587-590.

51 Engelman HS, MacDermott AB: Presynaptic ionotropic receptors and control of transmitter release. Nat Rev Neurosci 2004;5: 135-145.

52 Fisher SA, Fischer TM, Carew TJ: Multiple overlapping processes underlying shortterm synaptic enhancement. Trends Neurosci 1997;20:170-177.

53 Wall PD, Melzack R: Textbook of Pain. Edinburgh, Churchill Livingstone, 1999.

54 Treede RD, Meyer RA, Raja SN, Campbell $\mathrm{JN}$ : Evidence for two different heat transduction mechanisms in nociceptive primary afferents innervating monkey skin. J Physiol 1995;483:747-758.

55 Furue H, Katafuchi T, Yoshimura M: Sensory processing and functional reorganization of sensory transmission under pathological conditions in the spinal dorsal horn. Neurosci Res 2004;48:361-368. 